\title{
Imatinib Inhibits the Renewal and Tumorigenicity of CT-26 Colon Cancer Cells after Cytoreductive Treatment with Doxorubicin
}

\author{
Małgorzata Przybyszewska $^{1} \cdot$ Joanna Miłoszewska $^{1} \cdot$ Agnieszka Kotlarz $^{1}$. \\ Paweł Swoboda $^{1}$ - Kazimiera Pyśniak ${ }^{2}$ - Wojciech Szczepek ${ }^{3} \cdot$ Lukasz Kaczmarek $^{3}$ • \\ Sergiusz Markowicz ${ }^{1}$
}

Received: 26 June 2015/ Accepted: 20 January 2016/Published online: 8 March 2016

(C) L. Hirszfeld Institute of Immunology and Experimental Therapy, Wroclaw, Poland 2016

\begin{abstract}
Conventional anti-cancer drugs preferentially eliminate differentiated cancer cells but those cells that are spared (i.e. cancer stem cells: CSC), initiate recurrence. We tested whether drugs that target receptor tyrosine kinases (RTKs) involved in developmental signaling cascades and activated in CSC, could be used to silence and/or to eliminate colorectal cancer cells refractory to conventional treatment with cytoreductive drugs. A sequential treatment model was thereby developed with doxorubicin (DOX) and imatinib. CT-26 mouse colon carcinoma cells were pretreated with DOX to select DOX-refractory cells with CSC properties, which were then subsequently treated with RTK inhibitor imatinib, where their regrowth was found to be inhibited. Under both normoxic and hypoxic conditions, imatinib potently inhibited clonogenicity of DOX-refractory CT-26 cells. Treatment with DOX did not eliminate tumorigenic CT-26 cells, since CT-26 cells pre-exposed to DOX in vitro, when inoculated subcutaneously, induced tumors in $90 \%$ of mice, as opposed to a $100 \%$ rate in the case of chemonaive CT-26 cells. In mice inoculated with chemonaive CT-26 cells, tumor formation was not prevented by imatinib. However, imatinib prevented tumor formation in $50 \%$ of mice inoculated with CT-26 cells pre-
\end{abstract}

Małgorzata Przybyszewska

magip@coi.waw.pl

1 Department of Immunology, Maria Sklodowska-Curie Memorial Cancer Centre and Institute of Oncology, Roentgena 5, 02-781 Warsaw, Poland

2 Department of Genetics, Maria Sklodowska-Curie Memorial Cancer Centre and Institute of Oncology, ul. Roentgena 5, 02-781 Warsaw, Poland

3 Pharmaceutical Research Institute, Rydygiera 8, 01-793 Warsaw, Poland exposed to DOX in vitro, with the remaining $50 \%$ mice showing delayed tumor formation. These results suggest that the sequential use of the drug imatinib, as a drug targeting cancer cells expressing stem cell features after conventional cytoreductive treatment, is a promising future strategy for preventing tumor recurrence.

Keywords Colorectal cancer - Stemness - Imatinib Doxorubicin - Drug resistance $\cdot$ PDGFRs .

Sequential therapy

\section{Introduction}

Colorectal cancer is one of the major causes of cancer death worldwide, demonstrating increased rates of incidence and mortality (Ditkowska et al. 2009; Siegel et al. 2014). Conventional anti-cancer therapies based on cytotoxic systemic drugs and/or radiotherapy are often insufficient for curing advanced stage colorectal cancer. A growing body of evidence supports the notion that a small subset of cancer cells defined as tumor initiating cells (TIC) or cancer stem cells (CSC) are responsible for therapeutic failures. Cancer cells that retain stem cell properties are found to be more resistant to apoptosis induced by cytotoxic agents than differentiated tumor cells (Abdullah and Chow 2013; Dylla et al. 2008). Because of cancer cell plasticity, the stem-like phenotype can be induced in cancer cells refractory to conventional treatment (Kim et al. 2009; van der Horst et al. 2012). There is therefore a need for new therapeutic strategies to be developed that combine eradication of rapidly dividing differentiated cancer cells along with targeting the slowly dividing, drug resistant CSC and stem-like cells undergoing the epithelial-to-mesenchymal transition (Kong et al. 2011). 
Reactivation of the diverse developmental signaling cascades (involving EGF/EGFR, SCF/KIT, PDGF/ PDGFRs, VEGF/VEGFRs, SHH/PTCH/GLI and/or WNT/ $\beta$ catenin interactions), when combined with the increased intensity of DNA repair as well as with the ABC transporter-mediated multi-drug efflux, may contribute to resistance of colorectal CSC to conventional cytoreductive anti-cancer therapies (reviewed by Holohan et al. 2013; Klonisch et al. 2008). It thus appears likely that specific agents which inhibit one or multiple intrinsic and extrinsic pathways responsible for maintaining TIC/CSC, could be used to silence and/or eliminate TIC/CSC resistant to conventional therapy if these agents were sequentially administered post-treatment with conventional cytostatic drugs.

Platelet derived growth factors (PDGFs) drive the proliferation of undifferentiated mesenchymal cells and certain progenitor populations during early developmental stages (reviewed by Betsholtz et al. 2001). PDGFs affect tumor stem/progenitor cells in autocrine or paracrine fashion (Heldin 2012). PDGFs act as ligands binding to tyrosine kinase receptors PDGFR- $\alpha$ and PDGFR- $\beta$. The expression of PDGFRs, and especially the expression of PDGRF- $\beta$ isoform is responsible for the activation of proliferative and prosurvival signaling pathways within tumor cells. The mesenchymal and metastatic phenotype of invasive cancer cells can also be associated with the activity of the PDGF/PDGFR signaling pathway (Heldin 2013).

Imatinib has been developed as a selective inhibitor of BCR-ABL kinase for treating acute myeloid leukemia, but it is also capable of inhibiting with high specificity a subset of tyrosine kinases including PDGFRs, c-KIT, and c-ABL. The side effects of imatinib are relatively minor as compared to those observed with conventional chemotherapeutic drugs. Therefore, imatinib is considered a promising candidate agent to silence or eliminate drug-resistant cancer stem-like cells that survive previous treatment of solid tumors using conventional cytoreductive drugs.

In this study, we investigated whether imatinib could inhibit the renewal of colon cancer cells which survived treatment when the conventional cytoreductive drug doxorubicin (DOX) was used. We hypothesized that exposing CT-26 cells to DOX could select and/or induce a subpopulation of stem-like cells which are refractory to DOX but sensitive to imatinib. To determine whether imatinib treatment is effective in preventing cancer recurrence after cytoreductive treatment, we designed a two-step experimental model of sequential therapy using the CT-26 murine colon cancer cell line. It was previously found that CT-26 cells cultured in vitro express $\alpha$ and $\beta$ PDGF receptors and are sensitive to imatinib treatment (Lipiec et al. 2008). Under standard culture conditions, CT-26 cells display a spindle-shape phenotype of mesenchymal cells.
The CT-26 cell line also shares molecular features with undifferentiated, invasive human colorectal carcinoma cells (Castle et al. 2014). Furthermore, CT-26 cells inoculated into syngeneic or into nude mice are highly tumorigenic (Brattain et al. 1980). The CT-26 cell line can be thereby used as a valid cellular model corresponding to the metastatic and poorly differentiated human colorectal cancer.

\section{Materials and Methods}

\section{Tumor Cell Line and Mice}

The CT-26 colon carcinoma cell line established from a chemically-induced colorectal adenocarcinoma in BALB/c mice was purchased from ATCC (CRL-2638). CT-26 cells were cultured in RPMI 1640 medium supplemented with glutamine (Sigma-Aldrich, USA), $10 \%$ heat-inactivated fetal bovine serum (Lonza, Switzerland), and antibiotics: Streptomycin $100 \mu \mathrm{g} / \mathrm{ml}$, Penicillin $100 \mathrm{U} / \mathrm{ml}$ (Polfa, Poland). Cells were maintained under a humidified atmosphere with $5 \% \quad \mathrm{CO}_{2}$ at $37{ }^{\circ} \mathrm{C}$. Before injecting the syngeneic mice, CT-26 cells were suspended in phosphate buffered saline solution (PBS). Female BALB/c mice, aged 8 weeks, were obtained from the Department of Genetics at the Maria Sklodowska-Curie Memorial Cancer Centre and Institute of Oncology (Warsaw, Poland). Mice were maintained on standard laboratory chow and under pathogen-free conditions.

\section{Drugs}

Doxorubicin (DOX: Adriablastine, Pfizer, USA) stock solution $(2 \mu \mathrm{g} / \mathrm{ml})$ was frozen and stored at $-20{ }^{\circ} \mathrm{C}$ in the dark. After thawing, the DOX stock solution was appropriately diluted in culture medium. Imatinib (imatinib mesylate, polymorphic form $\alpha$ ) was synthesized in the Pharmaceutical Research Institute (Warsaw, Poland) (Szczepek et al. 2005, 2006). Imatinib was dissolved in a sterile, distilled water, and a $2 \mathrm{mM}$ stock solution of imatinib was frozen and stored at $-20{ }^{\circ} \mathrm{C}$ in the dark. Shortly before use, this solution was thawed and dissolved either in cell culture medium or dissolved in sterile distilled water supplemented with glucose intended for the oral administration to mice.

\section{Experimental Scheme for a Two-Step Sequential Therapy}

To determine the effect of imatinib on CT-26 colon carcinoma cells refractory to treatment at single dose of DOX, we designed the in vitro/in vitro and in vitro/in vivo models for a two-step sequential therapy (Fig. 1). During the 


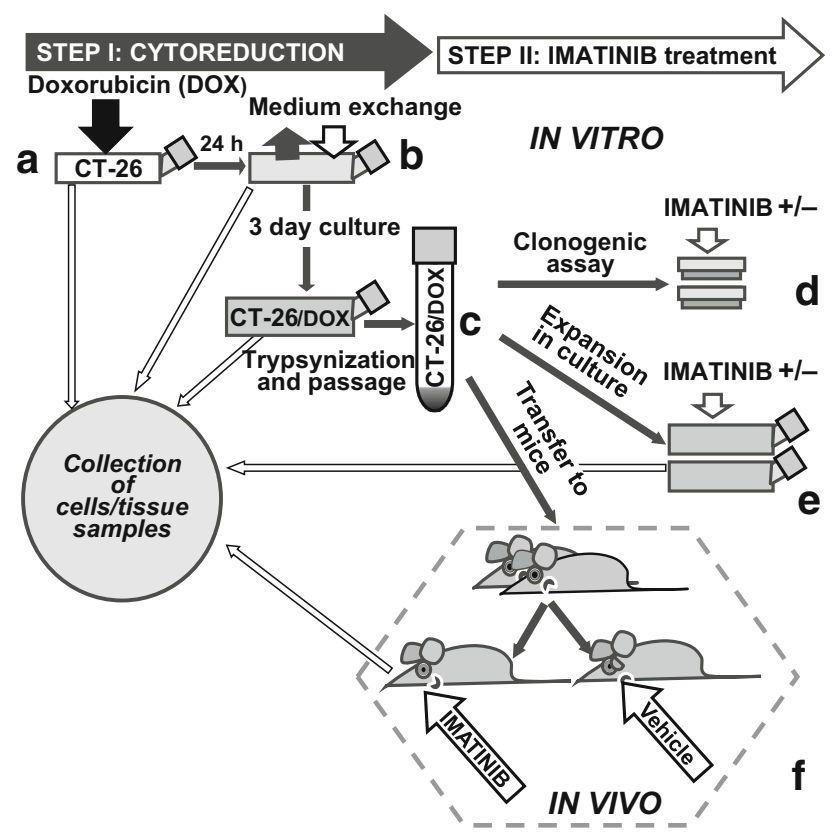

Fig. 1 The experimental scheme of two-step in vitro and in vivo treatment with DOX and imatinib. During the cytoreductive step (step I), CT-26 cells were exposed to DOX at a concentration of $0.1 \mu \mathrm{g} / \mathrm{ml}$ $(0.184 \mu \mathrm{M})$ for $24 \mathrm{~h}$ (a). The cytoreductive medium was then replaced with fresh medium without DOX, after which cells were cultured for 3 days (b). Following the cytoreductive step, DOXrefractory cells (CT-26/DOX cells) were collected (c) and then either passaged to be treated with imatinib in vitro (step II; $\mathbf{d}, \mathbf{e}$ ) or injected into mice for determining the effect of imatinib on CT-26/DOX cell tumorigenicity (step II; f). The imatinib $(10 \mu \mathrm{M})$ effect on CT-26/ DOX cell renewal in vitro was determined by a 10-day clonogenic assay (d) which counted clonogenic cells as well as in 4-day cultures for measuring cell expansion (e). Samples for real-time PCR analysis were collected from in vitro cultures on day 1 after DOX withdrawal and after completing the DOX-selection step (i.e. on day 3 after DOX withdrawal), and also on day 4 after CT-26/DOX cell passage (i.e. on day 7 after DOX withdrawal). Mice injected with CT-26/DOX cells were treated or untreated with imatinib. The experiments included the respective controls

cytoreductive step (step I), CT-26 cells were exposed to DOX. After the pre-selection, CT-26 cells refractory to DOX were exposed to imatinib either in vitro or in vivo (step II).

\section{Determining the DOX Effect on CT-26 Cell Clonogenicity}

For measuring the cytoreductive effect of DOX on clonogenic CT-26 cells, tumor cells were suspended in culture medium and seeded onto $30 \mathrm{~mm}$ plastic Petri dishes (ten dishes per group) at a density of $2 \times 10^{2}$ cells/dish. Four hours after cell plating, DOX was added to the medium at concentrations of $0.015,0.25,0.05,0.1$ or $0.2 \mu \mathrm{g} / \mathrm{ml}$. After $24 \mathrm{~h}$, the cytoreductive medium containing DOX was removed, and fresh culture medium added. On day 10 , cells were fixed and stained with crystal violet-ethanol solution, and colonies consisting of at least 20 cells were counted under the microscope at $40 \times$ magnification.

\section{Selection of CT-26 Cells Refractory to DOX Treatment}

CT-26 cells were plated into $75 \mathrm{~cm}^{2}$ flasks (Nunclon, USA) at a density of $1.5 \times 10^{6}$ cells $/ 20 \mathrm{ml}$ medium. DOX was added at a final concentration of $0.1 \mu \mathrm{g} / \mathrm{ml}(0.184 \mu \mathrm{M})$, i.e. the concentration determined as clonogenic $\mathrm{IC}_{90}$, to cells attached to the plastic. CT-26 cells were incubated with DOX for $24 \mathrm{~h}$. Then the medium with DOX was replaced with a fresh medium without DOX and cells were incubated for three days. After the cytoreductive step, CT-26 cells refractory to treatment with DOX (i.e. CT-26/DOX cells) were harvested using trypsin with EDTA (TrypsinEDTA, Lonza, Switzerland). Cell viability and yield were evaluated in an automated cell counter (Countess, Invitrogen, USA) using trypan blue staining. The proportion of late apoptotic/necrotic and viable cells was evaluated by flow cytometry. Cell samples for mRNA isolation were collected and frozen at $-80{ }^{\circ} \mathrm{C}$ on day 1 after DOX withdrawal and after completing DOX-selection step (i.e. on day 3 after DOX withdrawal).

\section{Determining the Imatinib Effect on CT-26 Cell and CT-26/DOX Cell Clonogenicity under Normoxic $\left(20 \% \mathrm{O}_{2}\right)$ or Hypoxic $\left(5 \% \mathrm{O}_{2}\right)$ Conditions}

CT-26 cells were preselected with DOX either under normoxic or hypoxic conditions. The respective control chemonaive CT-26 cells were cultured for 4 days, also either under normoxic or hypoxic conditions. Samples of $2 \times 10^{2}$ viable control CT- 26 cells or $2 \times 10^{3}$ viable CT26/DOX cells, were seeded onto $30 \mathrm{~mm}$ Petri dishes, and cultured for 10 days in the absence or in the presence of $10 \mu \mathrm{M}$ imatinib under normoxia or hypoxia. Clonogenic cell sensitivity to different imatinib doses was measured at imatinib doses ranging 5-15 $\mu \mathrm{M}$ under normoxic conditions. Imatinib was added to the cells attached to the plastic. The culture medium was not changed during the test. A $5 \% \mathrm{O}_{2}$ hypoxic environment was created in SANYO $\mathrm{N}_{2} / \mathrm{O}_{2} / \mathrm{CO}_{2}$ Incubator, model: MCO-19M (UV) (Panasonic). Colony diameter $(2 r)$ was measured, and colony surface area was calculated using $\pi r^{2}$ formula.

\section{MTT Assay}

CT-26/DOX and control CT-26 cells were seeded in 24 -well plates at $5 \times 10^{4}$ cells/well. After 4 days of culture with or without imatinib, dimethyl thiazolyl diphenyl 
tetrazolium salt (Sigma-Aldrich, USA) was added to the cells at a concentration of $0.5 \mathrm{mg} / \mathrm{ml}$ in the RPMI 1640 medium. Cells were then incubated for $3 \mathrm{~h}$ at $37{ }^{\circ} \mathrm{C}$. Purple formazan crystals were dissolved with isopropanol, added at a 1 to 1 ratio. Formazan absorbance was measured at a wavelength of $570 \mathrm{~nm}$, and corrected by subtracting the absorbance at $690 \mathrm{~nm}$ (i.e. background level). Each assay was performed in triplicate.

\section{Determining the Imatinib Effect on CT-26/DOX Cell Re-Growth}

Samples of $1.5 \times 10^{6}$ CT-26/DOX cells suspended in $20 \mathrm{ml}$ medium were plated into $75 \mathrm{~cm}^{2}$ flasks and cultured with or without $10 \mu \mathrm{M}$ imatinib for 4 days. Fresh medium, with or without imatinib, was exchanged after 2 days of culture. Cells were then trypsinized, and cell viability and yield were determined. Cell samples for mRNA isolation were frozen and stored at $-80{ }^{\circ} \mathrm{C}$.

\section{Flow Cytometry Analysis}

The expression of CD133 on CT-26 and CT-26/DOX cells was determined after culture with or without imatinib. Cells were washed with PBS without $\mathrm{Ca}^{2+} \mathrm{Mg}^{2+}$, and then harvested and dispersed by Accutase (Sigma-Aldrich, USA). Cells were stained with the PE-conjugated rat antimouse AC133 epitope of Prominin-1 (CD133) (eBioscience, USA). Irrelevant rat PE-IgG1 was used as an isotype control. Cell viability was determined after staining with 7-amino actinomycin D (7-AAD, Becton-Dickinson, USA) by flow cytometry. The expression of PDGFR- $\alpha$ (CD140a) was determined with PE-conjugated rat antimouse CD140a (clone APA5), and the expression of PDGFR- $\beta$ (CD140b) with APC-conjugated rat anti-mouse CD140b (clone APB5) monoclonal antibodies purchased from Invitrogen, USA.

\section{Magnetic Separation and Characteristics of $\mathrm{CD} 133^{+}$ and CD133 ${ }^{-}$CT-26 Cell Subsets}

The subpopulation of CT-26 cells highly expressing the AC133 epitope of CD133 protein was separated from CD133- cells on magnetic columns using the MACS Microbead System (Miltenyi, Germany), according to manufacturer's instructions. For measuring the growth rate of the isolated cell fractions, $33.3 \times 10^{3}$ of $\mathrm{CD}_{133^{+}}$or CD133- CT-26 cells were seeded onto $60 \mathrm{~mm}$ Petri dishes. Cells were harvested and counted on day 7 after seeding. The clonogenicity assay of isolated cell subsets was performed in the presence of $10 \mu \mathrm{M}$ imatinib or $0.1 \mu \mathrm{g} / \mathrm{ml}$ $(0.184 \mu \mathrm{M}) \mathrm{DOX}$ as described for unseparated CT-26 cells. To establish whether the expanded CD133-positive cells maintain their clonogenic potential, a colony formation assay was performed with freshly isolated $\mathrm{CD}_{133^{+}}$cells and with $\mathrm{CD}_{133^{+}}$cells cultured for 2 weeks under standard cell culture conditions.

\section{In Vivo Assays}

\section{Treatment of Mice with Imatinib after Tumor Cell Inoculation}

BALB/c mice were subcutaneously injected with $5 \times 10^{4}$ CT-26/DOX cells or with $5 \times 10^{4}$ chemonaive CT-26 cells in the dorsal skin. Step II of the in vitro/in vivo treatment was started on day 2 after inoculating the mice with cancer cells (Fig. 1). Groups of mice injected with either CT-26/ DOX or with control CT-26 cells, were divided into subgroups of those untreated or treated with imatinib. In the latter groups, each mouse once daily received orally $1.5 \mathrm{mg}$ of imatinib ( $75 \mathrm{mg} / \mathrm{kg}$ of body weight) dissolved in $50 \mu \mathrm{l}$ of dist. $\mathrm{H}_{2} \mathrm{O}$ with glucose constituting the drug vehicle. The mouse control groups received only the vehicle. Subgroups of mice injected with CT-26 cells untreated or treated with imatinib each consisted of ten mice, and subgroups of mice injected with CT-26/DOX cells consisted each of 20 mice. Administering imatinib or the vehicle was continued for 14 days, i.e. until the first tumors appeared in the controls injected with chemonaive CT-26 cells. All mice were weighed before and after therapy. The time-point was noted at which any palpable tumor had been diagnosed. Tumors were measured twiceweekly. Tumor volume was calculated according to the modified rotating ellipsoid volume formula $V_{\text {Tumor }}=\pi /$ $6 \mathrm{a}^{2} \mathrm{~b}\left(0.52 \times\right.$ width ${ }^{2} \times$ length $)$.

\section{Collecting of Tumor Samples for Histological and Molecular Examination}

In order to examine the effect of imatinib on tumor cells derived from the implanted cells, two groups of mice were injected with either CT-26 cells or CT-26/DOX cells. To accelerate tumor induction and growth, each mouse was injected with $2 \times 10^{5}$ cells. Mice were then treated with imatinib or kept untreated until autopsy. Subgroups of mice injected with either CT-26 cells or CT-26/DOX cells and subsequently treated or untreated with imatinib consisted each of ten mice. Tumors were excised from individual mice. Samples were obtained from 5 to $8 \mathrm{~mm}$ diameter tumors. Material was divided by half for either histological and molecular examination. Tumor samples for RNA analysis were immediately frozen at $-80{ }^{\circ} \mathrm{C}$. The other tumor samples were fixed in $10 \%$ buffered formalin solution (Sigma-Aldrich, USA) and embedded in paraffin for histological and immunohistochemical examination. 


\section{Histology and Immunohistochemistry}

Sections of $4 \mu \mathrm{m}$ were cut from the paraffin-embedded tumor samples, dewaxed with xylene, gradually rehydrated and then stained with hematoxylin and eosin (H\&E), according to standard procedure. Immunohistochemistry reagents were purchased from Dako, Denmark. Endogenous peroxidase activity in the sections was blocked by incubation with the dual endogenous enzyme block for $30 \mathrm{~min}$. All studied sections were boiled in target retrieval solution $(\mathrm{pH}$ 9) for $20 \mathrm{~min}$. After cooling and washing twice for $5 \mathrm{~min}$ with washing buffer, the histology and immunohistochemistry (IHC) reactions were performed using rabbit polyclonal anti-Ki 67 antibodies diluted 1:200 (Abcam, UK), antimouse AC133 epitope of Prominin-1 (CD133; Santa Cruz, USA) and anti-vimentin (R\&D, USA). Tested sections were incubated with antibodies accordingly to the manufacturers' instructions. The test antigen was visualized using biotinylated antibodies, the streptavidin-biotinylated peroxidase complex (Universal Dako LSAB + kit, Peroxidase, Code K0679) and diaminobenzidine. All sections were shortly afterwards counterstained with Meyer's hematoxylin. The test procedure included a negative control in which the specific antibody was substituted by PBS.

\section{Real-Time PCR Analysis}

Total RNA was isolated using Trizol-based reagent extraction. RNA quality was assessed by the $A_{260} / A_{280}$ ratio. Two micrograms of RNA was used for cDNA synthesis as performed by the High Capacity RNA-to-cDNA ${ }^{\mathrm{TM}}$ Kit (Thermo Scientific, USA). Real-time PCR for Cd133, Bcrpl, Vegf- $a$, $C d 31$, Pdgfra, Pdgfrb, i.e. genes associated with CSC phenotype, drug resistance or angiogenesis, was carried out in triplicates, using TaqMan Gene Expression Assays (Thermo Scientific, USA). Data was analyzed by the ddCT method using Tbp and Actb as an endogenous controls. The comparative CT method was used with $T b p$ serving as an endogenous control. The data output was expressed as a foldchange of expression levels. Fold differences, calculated using the $\Delta \Delta C_{\mathrm{T}}$ method, were expressed as a range which is the result of incorporating the standard deviation of the $\Delta \Delta C_{\mathrm{T}}$ value into the fold-difference calculation.

\section{Statistical Analysis}

Statistical significance of parametric data was assessed by the Student's $t$ test, while non-parametric data were assessed by the Kruskal-Wallis test and the Mann-Whitney $U$ tests using SSPS 14.0 program (SPSS Inc.). Values of $p<0.05$ were considered significant.

\section{Results}

The ultimate goal of our study was to determine whether imatinib could inhibit renewal and reduce tumorigenicity of the CT-26 colon cancer cell population resistant to treatment with a conventional cytoreductive drug. We have thus developed in vitro/in vitro and in vitro/in vivo experimental models of a two-step therapy with DOX and imatinib (Fig. 1). In the first step of the sequential treatment scheme, CT-26 cells were exposed for one day to DOX $(0.1 \mu \mathrm{g} / \mathrm{ml})$, and for the next three days cultured without DOX to select cells refractory to cytoreduction. The concentration of DOX $\left(\mathrm{IC}_{90}\right)$ used to select cells refractory to cytoreductive treatment was determined by the preliminary clonogenicity assays performed under normoxic culture conditions with DOX at concentrations ranging $0.015-0.2 \mu \mathrm{g} / \mathrm{ml}$ (data not shown). In the second step of the in vitro/in vitro treatment scheme, we measured the effect of imatinib on the renewal of CT-26 cells preselected with DOX at $\mathrm{IC}_{90}$ (CT-26/DOX cells).

Chemonaive CT-26 cells and CT-26/DOX cells expressed Pdgfra and Pdgfrb mRNA. The expression of $P d g f r b$ mRNA was higher in CT-26/DOX cells on day 3 after DOX withdrawal and on day 4 after cell passage, under normoxic as well as under hypoxic $\left(5 \% \mathrm{O}_{2}\right)$ culture conditions, compared to chemonaive CT-26 cells, whilst the expression of Pdgfra mRNA was higher in CT-26/DOX cells only under normoxia (Fig. 2a). The expression of PDGFR- $\alpha$ and PDGFR- $\beta$ on cell surface of CT- 26 cells and CT-26/DOX cells was confirmed by flow cytometry (Fig. 2b).

The proportion of colony-forming cells in the CT-26/ DOX cell population, collected on day 3 after the exposure to DOX at a concentration of $0.1 \mu \mathrm{g} / \mathrm{ml}$, was ten times lower than in the control chemonaive CT-26 cells (Fig. 3a). Imatinib inhibited colony formation by chemonaive CT-26 cells and CT-26/DOX cells in a dose dependent manner (Fig. 3b). Clonogenic CT-26/DOX cells were much more sensitive to the inhibitory effect of imatinib than chemonaive clonogenic CT-26 cells. Imatinib $(10 \mu \mathrm{M})$ reduced the number of colonies formed by chemonaive CT-26 cells by half, whereas the number of colonies formed by CT-26/DOX cells in the presence of imatinib, was 25 times lower than in the absence of imatinib. Effects of sequential exposure to $\mathrm{DOX}$ at $\mathrm{IC}_{90}$ and to $10 \mu \mathrm{M}$ imatinib were cumulative. Only $0.11 \%$ of CT-26/DOX cells exposed to $10 \mu \mathrm{M}$ imatinib formed colonies under normoxic culture conditions, whereas $2.5 \%$ of CT-26/ DOX cells and $24 \%$ of chemonaive CT-26 cells formed colonies in the absence of imatinib under normoxic culture conditions. 

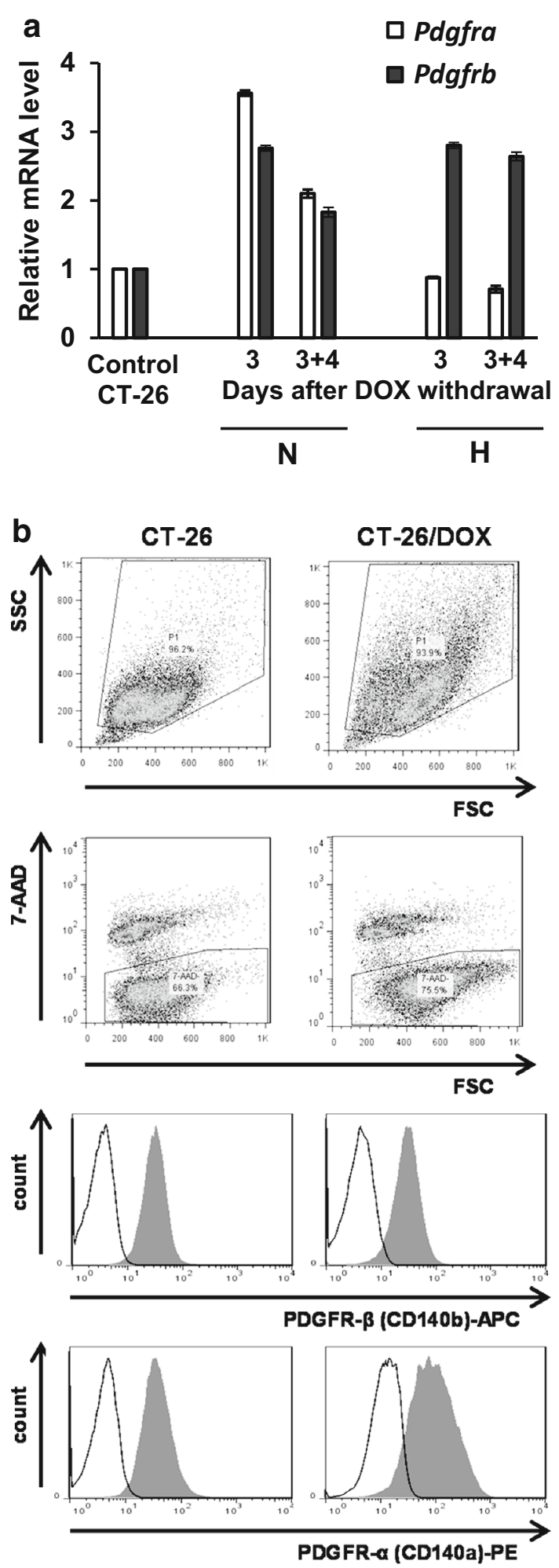

unstained control

stained samples
4Fig. 2 Chemonaive CT-26 cells and CT-26/DOX cells express Pdgfra and Pdgfrb mRNA under normoxic (N) as well as under hypoxic $(\mathrm{H})$ culture conditions. Fold-differences of mRNA level in CT-26/DOX cells, compared to mRNA levels in control CT-26 cells, were calculated using the $\Delta \Delta C_{\mathrm{T}}$ method, and are expressed as a range which is the result of incorporating the standard deviation of the $\Delta \Delta C_{\mathrm{T}}$ value into the fold-difference calculation (a). PDGFR- $\alpha$ and PDGFR- $\beta$ expression on cell surface, measured by flow cytometry, is shown for chemonaive CT-26 cells cultured under normoxic condition and CT-26/DOX cells selected under normoxic condition (b). Flow cytometry analysis is shown for CT-26/DOX cells collected on day 3 after DOX withdrawal. Both PDGFR receptors were expressed by CT-26/DOX cells also on day 4 after cell passage (data not shown). FSC forward scatter, SSC side scatter, 7-AAD 7-amino actinomycin $\mathrm{D}, P E$ phycoerythrin, $A P C$ allophycocyanin

Since hypoxia is considered as being an important factor of the tumor microenvironment mediating drug resistance and promoting stemness of cancer cells, the effect of imatinib on the clonogenicity of CT-26 cells and of CT-26/ DOX cells was compared under normoxic and under mild hypoxic culture conditions $\left(5 \% \mathrm{O}_{2}\right)$. Imatinib $(10 \mu \mathrm{M})$ inhibited colony formation by chemonaive CT-26 cells more potently under hypoxia than under normoxia (Fig. 4a; left panel). Proportions of clonogenic cells were higher in CT-26/DOX cells preselected under hypoxia compared to CT-26/DOX cells preselected under normoxia (Fig. 4a; right panel). In the absence of imatinib, CT-26/DOX cells developed a higher numbers of colonies in the clonogenic assay under hypoxia than normoxia. Imatinib also potently inhibited colony formation by CT-26/DOX cells under hypoxia and under normoxia where imatinib inhibition was higher in the former compared to the latter.

In the clonogenic assay, middle size dispersed colonies (M) with a mean surface area of $0.63 \times 10^{6} \mu \mathrm{m}^{2}$, and large dense colonies (L/D), with a mean surface area of $1.57 \times 10^{6} \mu \mathrm{m}^{2}$, were together preponderant in colonies formed by chemonaive CT-26 cells and by CT-26/DOX cells preselected under hypoxia, but not in colonies formed by CT-26/DOX cells preselected under normoxia (Fig. 4b; left panel). Middle size colonies resembled paraclones or spheroidal clones consisting of cells loosely adherent to the plastic surface. A majority of colonies formed by CT-26 cells and by CT-26/DOX cells in the presence of imatinib were small colonies $(\mathrm{S})$ with a mean surface area of $0.18 \times 10^{6} \mu \mathrm{m}^{2}$. Imatinib abolished the promoting effect of hypoxia on the proliferation of cells forming colonies. CT-26/DOX cells cultured with $10 \mu \mathrm{M}$ imatinib under hypoxia did not form L/D and M colonies. Our data show that the inhibitory effect of imatinib on the renewal of CT26/DOX cells was manifested by both a decreased proportion of clonogenic cells in the CT-26/DOX cell population together with a reduced yield of cells generated within colonies under normoxia and under hypoxia. 
Fig. 3 The effect of DOX and imatinib on colony formation by CT-26 cells. The efficiency of colony formation by CT-26 cells preselected with DOX at a concentration of $0.1 \mu \mathrm{g} / \mathrm{ml}$ $(0.184 \mu \mathrm{M})(\mathrm{CT}-26 / \mathrm{DOX})$ was ten times lower than chemonaive CT-26 cells (a). Each symbol in a represents mean \pm SD of colony count in groups of $n=5$ plates.

Clonogenic CT-26/DOX cells were more sensitive to the inhibitory effect of imatinib than chemonaive clonogenic CT-26 cells (b). The bar graphs in $\mathbf{b}$ indicate mean $\pm \mathrm{SD}$ of colony count in groups of $n=10$ plates. Because of the lower clonogenic potential of CT-26/DOX cells, the effect of imatinib was determined after plating chemonaive CT-26 cells at a density of 200 cell/dish, and CT-26/DOX cells at a density of $2000 \mathrm{cell} / \mathrm{dish}$
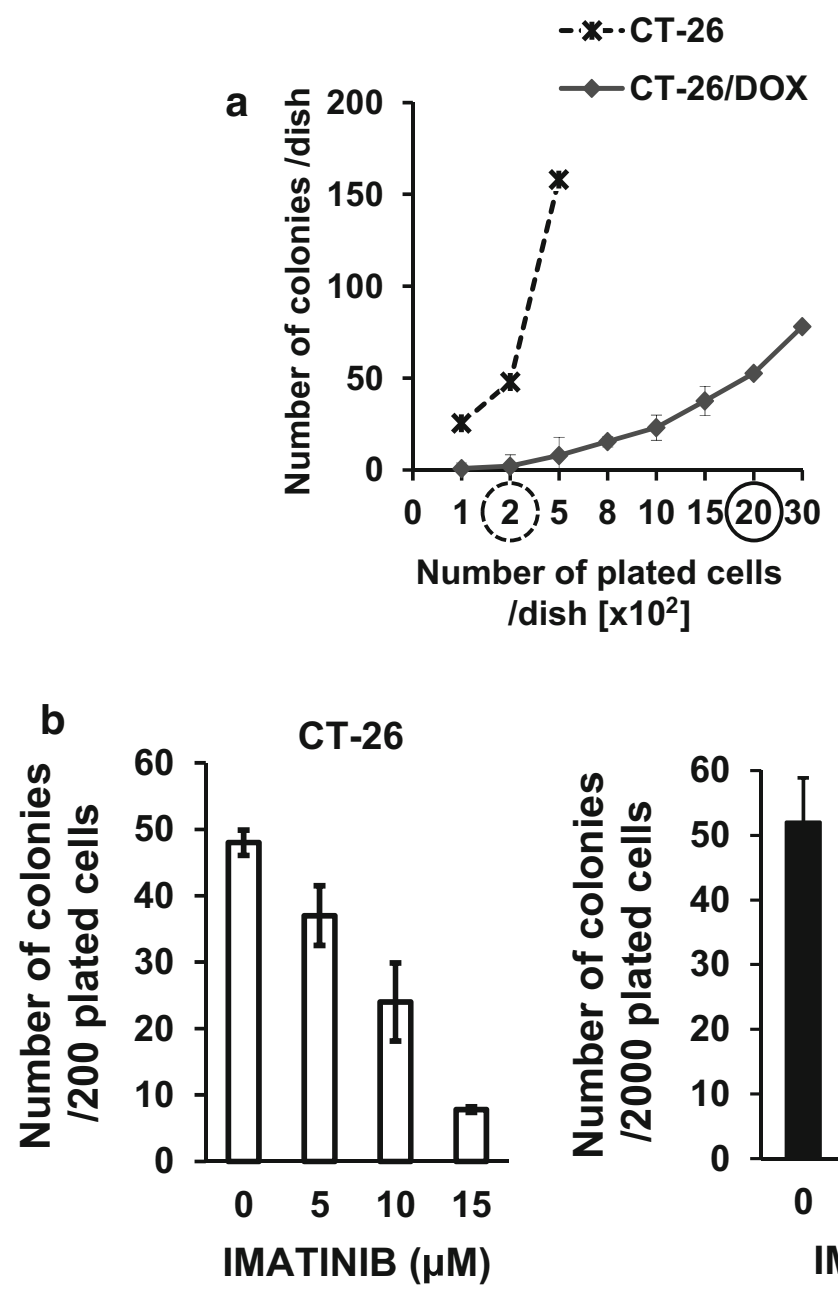

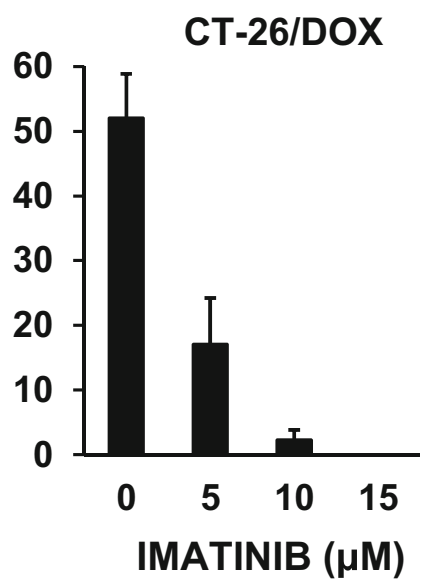

The renewal of CT-26 cells refractory to a single DOX dose was started after the removal of DOX from the culture, however the growth rate of these cells during 3 days after the removal of DOX was lower compared to nontreated chemonaive CT-26 cells (Fig. 5). CT-26/DOX cells continued to expand after passage, although much less efficiently compared to chemonaive CT-26 cells. Imatinib inhibited expansion of CT-26/DOX cells. A proportion of late apoptotic/necrotic cells, as determined by flow cytometry analysis with 7-AAD dye staining, was higher in CT-26/DOX cells collected on day 4 of culture with or without imatinib than in chemonaive CT-26 cells. This suggests that the inhibition of CT-26/DOX cell expansion after passage was at least in part due to cell necrosis or/and apoptosis. The exposure to DOX profoundly changed the appearance of CT-26 cells. Three days after the DOX removal, cells exposed to DOX remained enlarged, highly granular, flattened and strongly adherent (Fig. 5). Four days after cell passage, the CT-26/DOX cells cultured with imatinib remained enlarged and flattened. The CT-26/DOX cell population cultured without imatinib consisted of many foci of small proliferating cells resembling chemonaive CT-26 cells. These foci of small cells were dispersed among the enlarged cells.

The MTT assay results demonstrated a proliferative activity of CT-26/DOX cells that was substantially reduced compared to chemonaive CT-26 cells, but was not further reduced in the presence of $10 \mu \mathrm{M}$ imatinib. The effect of imatinib on the proliferation of chemonaive CT-26 cells was less pronounced than the effect with DOX pretreatment at a concentration of $0.1 \mu \mathrm{g} / \mathrm{ml}$ (Fig. 6). We found that MTT assay was not appropriate to detect imatinib effect on the renewal of CT26/DOX cells after passage.

It is debatable whether the expression of AC133 epitope of CD133 is associated with the stemness and tumorigenicity of colon cancer cells (Irollo and Pirozzi 2013). We have found that $2.74 \pm 0.79 \%$ (mean $\pm \mathrm{s}$ tandard deviation (SD); $n=5$ independent experiments) of chemonaive CT-26 cells express the AC133 epitope of CD133. A proportion of cells expressing CD133 in CT26/DOX cell population on day 3 after DOX withdrawal (Fig. 7, row B) was lower than in the control chemonaive 
a

\section{CT-26}
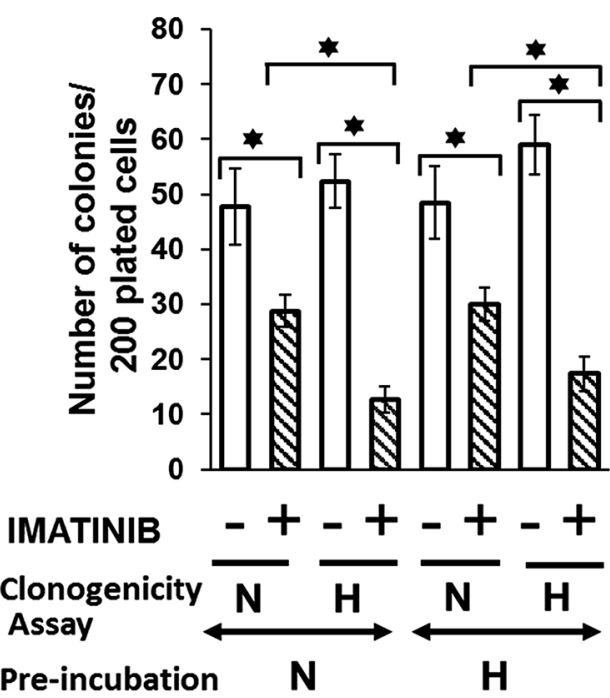

\section{CT-26/DOX}
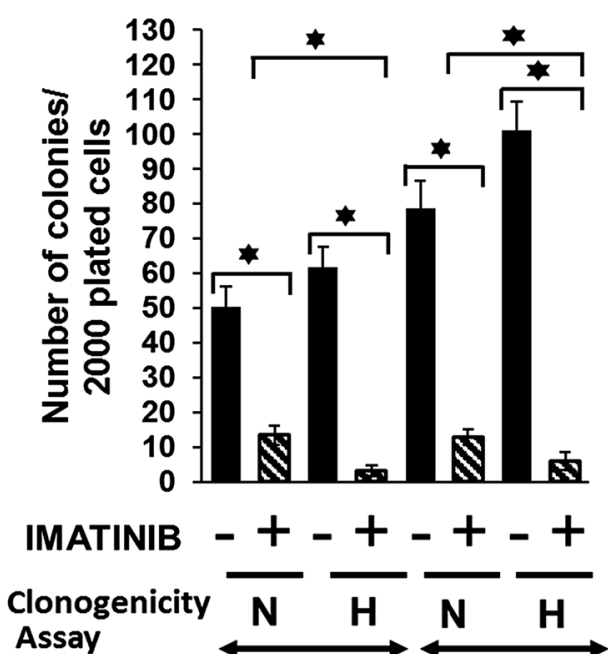

Pre-selection

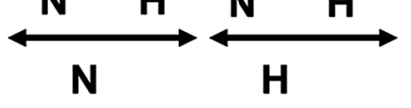

b
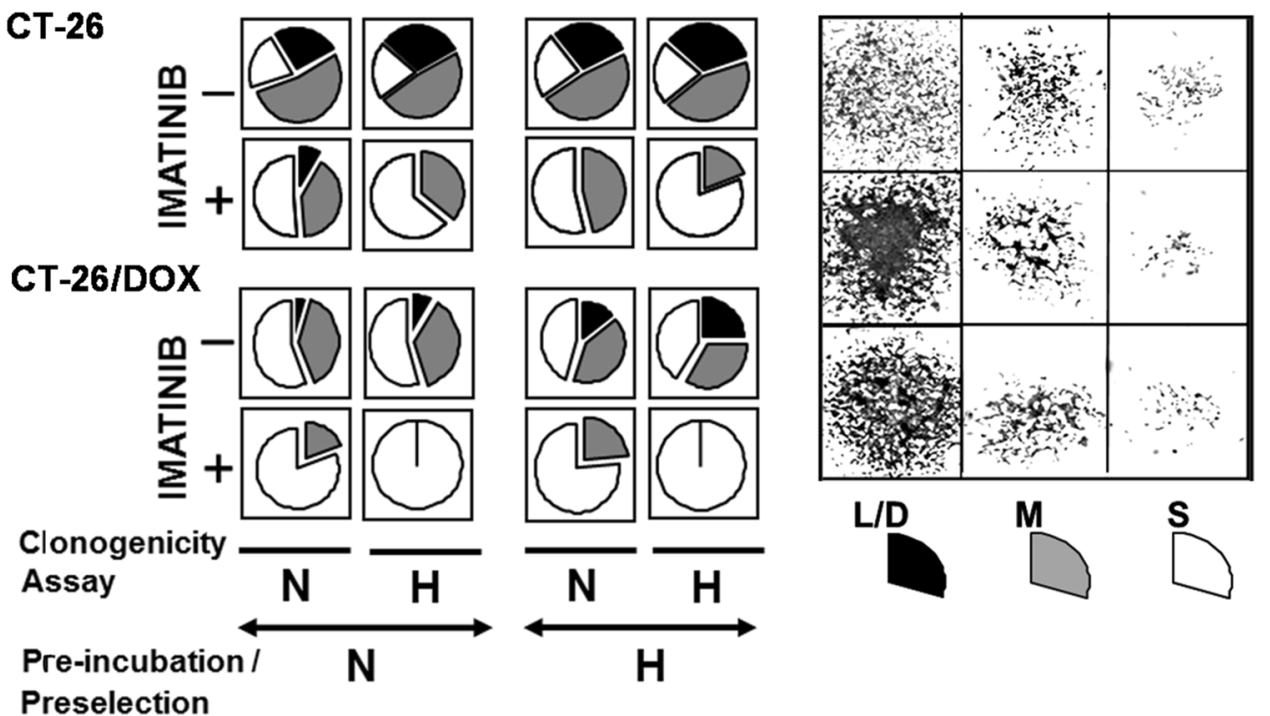

Preselection

Fig. 4 Comparing the effect of imatinib on the clonogenicity of chemonaive CT-26 cells and CT-26/DOX cells under normoxic $(\mathrm{N})$ and under hypoxic conditions (H). CT-26 cells were preselected with DOX under normoxia or hypoxia. To maintain comparability of treatment conditions, control CT-26 cells were respectively preincubated in normoxia or in hypoxia conditions. Chemonaive CT-26 cells and CT-26/DOX cells and were seeded at a cell density appropriate to the clonogenic potential of each of these cell populations. The colonyforming cell number per 200 plated CT-26 cells and per 2000 plated CT-26/DOX cells (a), and the proportion of different colony types classified on the basis of clone size and density as large/dense

CT-26 cells (Fig. 7, row A), but increased after passage of CT-26/DOX cells (Fig. 7, row C). Nevertheless, the expression level of CD133, measured by fluorescence indices in the rebounding $\mathrm{CD} 133^{+}$cell subset of CT-26/ colonies (L/D), middle size colonies (M) or small colonies (S) was measured (b). Pie graphs are shown in the left panel of $\mathbf{b}$ and demonstrate proportions of different colony types according to the bars shown in a. The bar graphs in a indicate mean \pm SD of colony count in each experimental groups consisting of $n=10$ plates. Statistical differences between groups were determined by the MannWhitney test. An asterisk indicates a significant difference at $p<0.05$. The microphotographs shown in the right panel of b show the representative appearance of the colony types formed by CT-26/DOX cells

DOX cells, was lower than in the chemonaive CD133 CT-26 cells. Imatinib inhibited renewal of CD133-expressing CT-26/DOX cells (Fig. 7, row D). The decreased expression level of CD133 on the cell surface as well as 
Fig. 5 Effect of sequential treatment with DOX and imatinib on CT-26 cell yield, mortality and cells appearance in culture. Cells harvested after culture were stained with the 7-AAD dye to determine a proportion of late apoptosis/ necrosis by flow cytometry analysis. $10^{5}$ viable chemonaive CT-26 cells and $10^{5}$ of viable CT-26/DOX cells were seeded in the cultures. The experiment shown is representative of the three performed

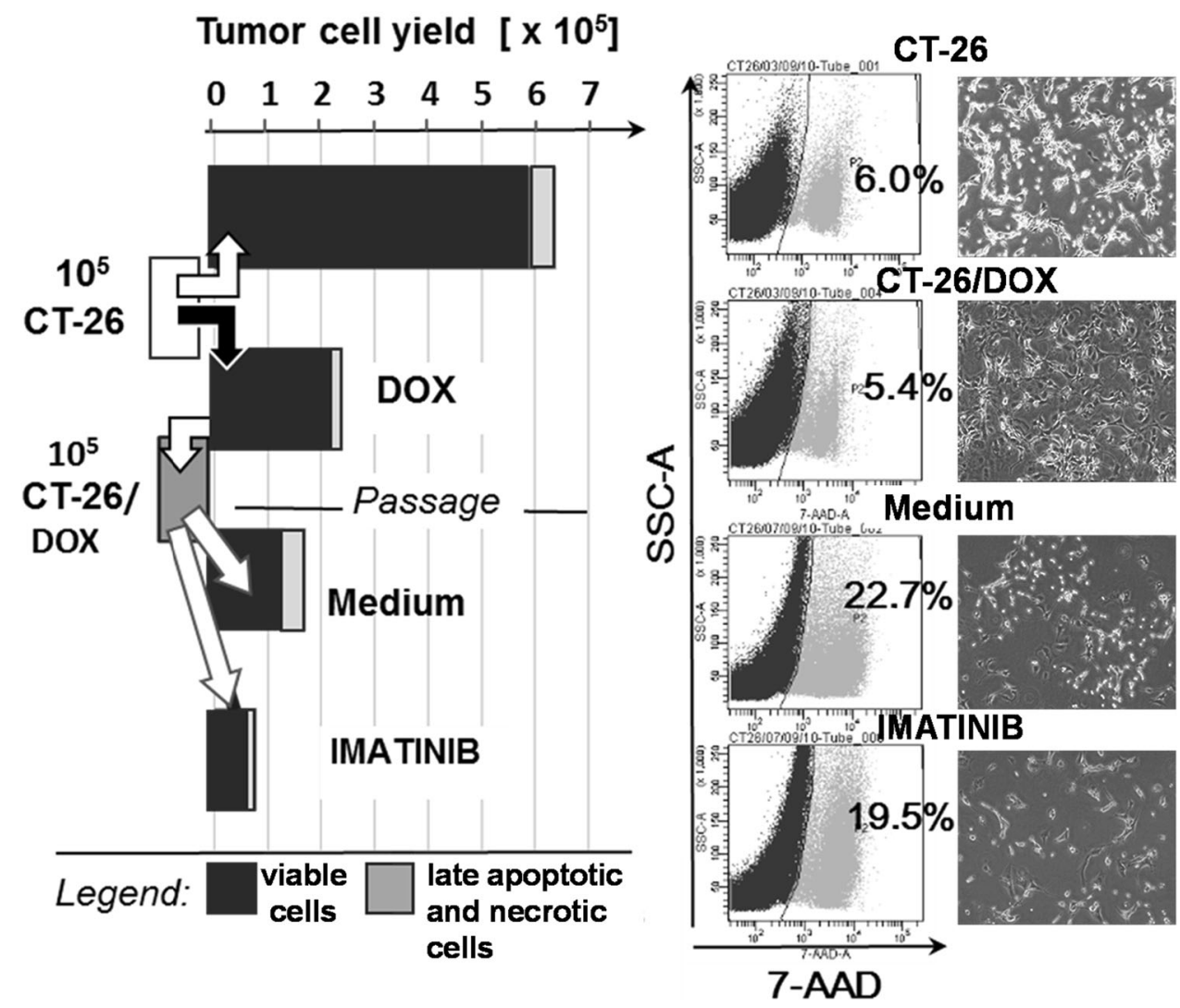

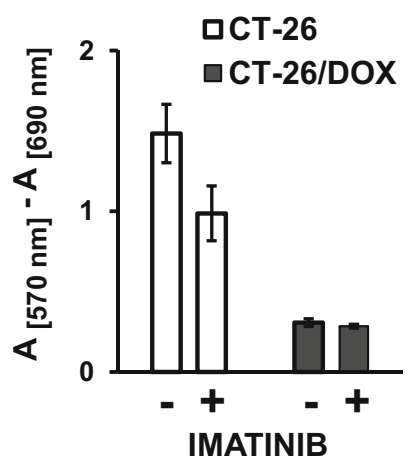

Fig. 6 The effect of imatinib on the viability of CT-26 cells and CT26/DOX cells measured by the MTT. The bar graphs indicate mean \pm SD of $n=6$ absorbance $(A)$ measurements in each experimental group

the decreased proportion of CD133 ${ }^{+}$CT-26/DOX cells, contrasted with the increased relative expression of Cd133 mRNA on day 3 after withdrawal of DOX and also after 4-day culture with imatinib (Fig. 8a). The relative expression level of Bcrpl mRNA was higher in CT-26 cells on day 3 then on day 1 after withdrawal of DOX, which remained increased following cell passage and 4-day culture with or without imatinib in compared to control chemonaive cells (Fig. 8b). This observation suggests that CT-26/DOX cells may have increased drug efflux capability compared to chemonaive CT-26 cells.

A separation of CT-26 cells on magnetic columns using the anti-AC133/CD133 antibody provided the CD133 ${ }^{+}$and $\mathrm{CD}_{133^{-}}$cell fractions that differently expressed $C d 133$ mRNA. However, the expression of Bcrpl and Vegf$a$ mRNA was similar in these cell fractions (Fig. 9a). The proliferative potential of $\mathrm{CD} 133^{+} \mathrm{CT}-26$ cells was higher than in $\mathrm{CD}_{133^{-}} \mathrm{CT}-26$ cells. This manifested by 67 -fold expansion of $\mathrm{CD} 133^{+} \mathrm{CT}-26$ cells compared to a 33 -fold expansion of $\mathrm{CD}_{133^{-}}$cells after 7 days of culture (data not shown).

Freshly isolated $\mathrm{CD} 133^{+} \mathrm{CT}-26$ cells contained a higher proportion of clonogenic cells than total CT-26 cells (Fig. 9b). Both chemonaive $\mathrm{CD}_{133^{+}}$and $\mathrm{CD} 133^{-}$clonogenic CT-26 cells were highly sensitive to DOX, and to a lesser degree to imatinib (Fig. 9b). The clonogenicity of $\mathrm{CD}_{133^{+}}$cell fraction after 2 -week culture became similar to the clonogenicity of total CT-26 cells (Fig. 9c).

We then compared the effects of imatinib on the tumorigenicity of chemonaive CT-26 cells and CT-26/ DOX cells. Chemonaive CT-26 cells induced palpable tumors in $100 \%$ of mice within 14-22 days after tumor cell inoculation, whereas the same number of CT-26/DOX cells induced tumors in $90 \%$ of mice between days 22 and 51 (Fig. 10). Time-laps between tumor cell inoculation and 
Fig. 7 Comparing CD133 expression in chemonaive CT26 cells (row a), CT-26/DOX cells collected on day 3 after withdrawal of $0.184 \mu \mathrm{M}$ DOX (row b), CT-26/DOX cells cultured in the absence of imatinib (row c) or with $10 \mu \mathrm{M}$ imatinib (row d) for 4 days after cell passage. Percentages of cells displayed in a gate set for $\mathrm{CD}_{133^{+}}$are shown in samples stained with isotype control $\mathrm{Ab}$ and with $\mathrm{Ab}$ specific to CD133. Fluorescence indices of cells stained positive with $\mathrm{PE}$ conjugated anti-CD133 $\mathrm{Ab}$ in such cell populations were respectively 146 (a), 16.8 (b), 8.9 (c) and 9.4 (d). To calculate the fluorescence index of cells stained positive, a mean fluorescence intensity of cells gated as $\mathrm{CD}_{133^{+}}$was divided by a mean fluorescence intensity of cells gated as CD133negative in samples incubated with PE-conjugated anti-CD133 $\mathrm{Ab}$. The experiment shown is representative of the three performed

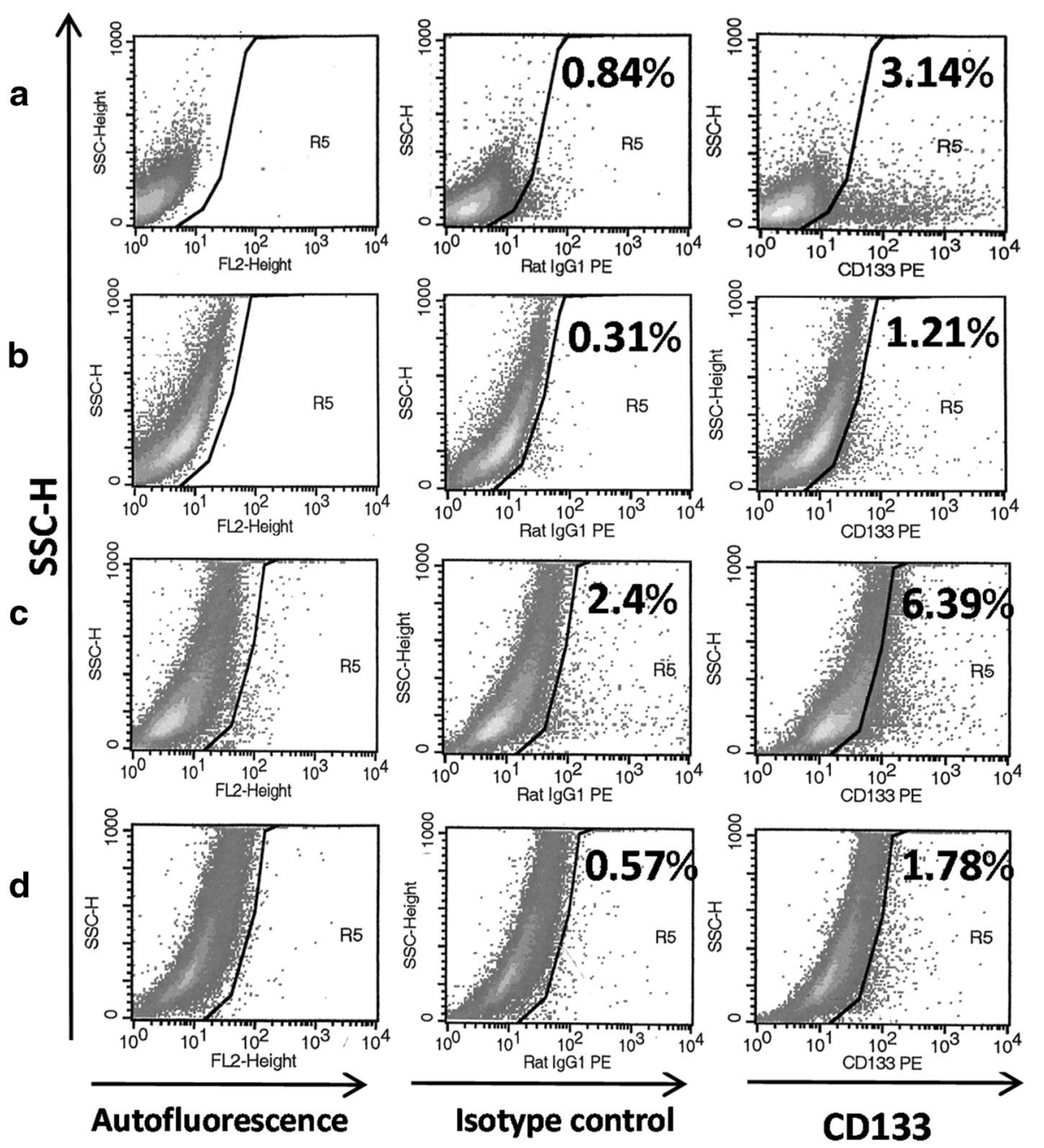

the first diagnosis of palpable tumor was 7 days longer in the CT-26/DOX cell-bearing mice group than in the group of mice bearing CT-26 cells. Tumor formation was not substantially delayed in the majority of mice inoculated with chemonaive CT-26 cells receiving $1.5 \mathrm{mg}$ of imatinib once daily for 14 days compared to mice not receiving imatinib. All these mice developed tumors within 31 days after tumor cell inoculation. Administration of imatinib delayed tumor development or prevented mice from tumors initiated by CT-26/DOX cells. The $50 \%$ of mice in the group inoculated with CT-26/DOX cells and treated with imatinib developed tumors within 31 and 68 days, whilst the other $50 \%$ of mice in this group never developed any tumors during 3-month observation. The prolonged tumorfree survival of mice treated with imatinib after inoculation with CT-26/DOX cells, was accompanied by a reduced growth rate of tumors in those mice which developed tumors compared to the mice untreated with imatinib
(Fig. 11). This data demonstrates that treatment solely with imatinib does not prevent mice from having tumors initiated by chemonaive CT-26 colon cancer cells. However, imatinib substantially delays tumor development or indeed prevents mice from having tumors initiated by cells refractory to treatment with the conventional cytoreductive drug DOX.

We measured mRNA expression levels of selected genes associated with stemness, drug resistance and/or angiogenesis in tumors initiated by chemonaive CT-26 cells or CT-26/DOX cells. The relative expression level of $C d 133$ mRNA was similar in tumors initiated by CT26 cells in the control group and in mice treated with imatinib until autopsy (Fig. 12). However, the relative expression level of Cd133 mRNA in tumors initiated by CT-26/DOX cells was higher in mice treated with imatinib than in mice untreated with imatinib. The expression level of Bcrpl, Vegf-a, and $C d 31 \mathrm{mRNA}$ did 

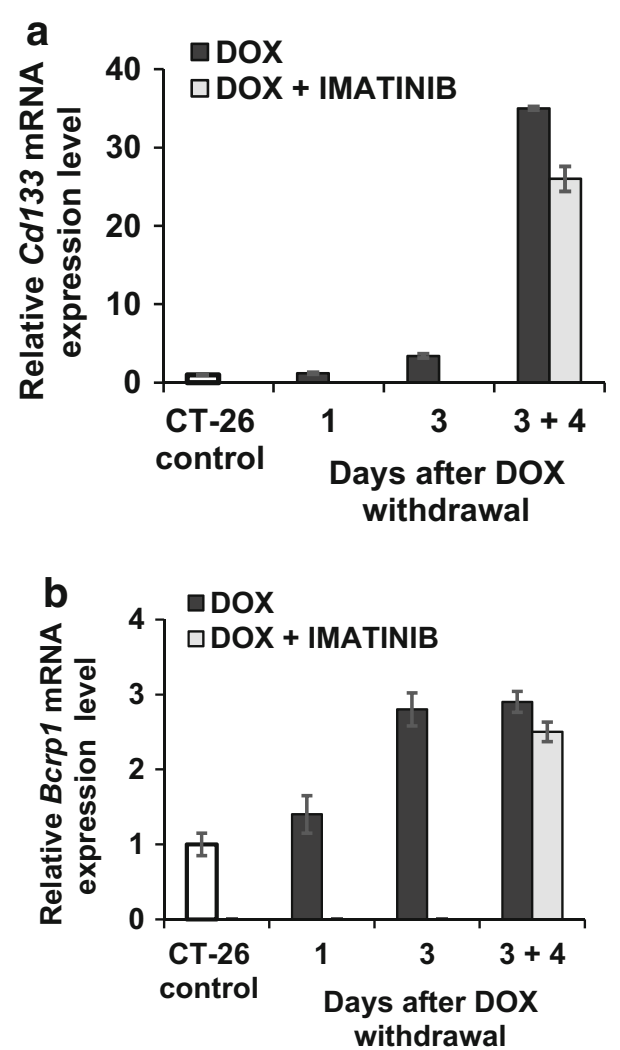

Fig. 8 The relative mRNA expression of Cd133 (a) and Bcrp1 (b) determined by real-time PCR in chemonaive CT-26 cells (the control level), in CT-26/DOX cells on day 1 and on day 3 after withdrawal of DOX, and in CT-26/DOX cells cultured with or without imatinib for 4 days after cell passage. Fold-differences calculated using the $\Delta \Delta C_{\mathrm{T}}$ method are expressed as a range which is the result of incorporating the standard deviation of the $\Delta \Delta C_{\mathrm{T}}$ value into the fold-difference calculation

not substantially differ in tumors collected from mice inoculated with CT-26 cells or with CT-26/DOX cells and then subsequently treated or untreated with imatinib.

By IHC analysis, we found fewer less cells expressing $\mathrm{Ki}-67$ at the edge and in the center of tumors collected from mice treated with imatinib than from mice untreated following inoculation with CT-26/DOX cells (Fig. 13). Numerous tumor buds protruding from the tumor edge to the tumor margin were found in tumors collected from mice untreated with imatinib after inoculation with CT-26/ DOX cells, but only a few in tumors collected from mice treated with imatinib. Tumor buds forming crypt-like structures in the invasive front of tumor stained strongly with anti-Ki-67 antibodies, but did not stain with antibodies recognizing the AC133 epitope of the CD133 molecule (Fig. 14). CD133 was not found in tumor tissue by IHC methods, although $C d 133$ mRNA expression was detected in the same tumor specimens.
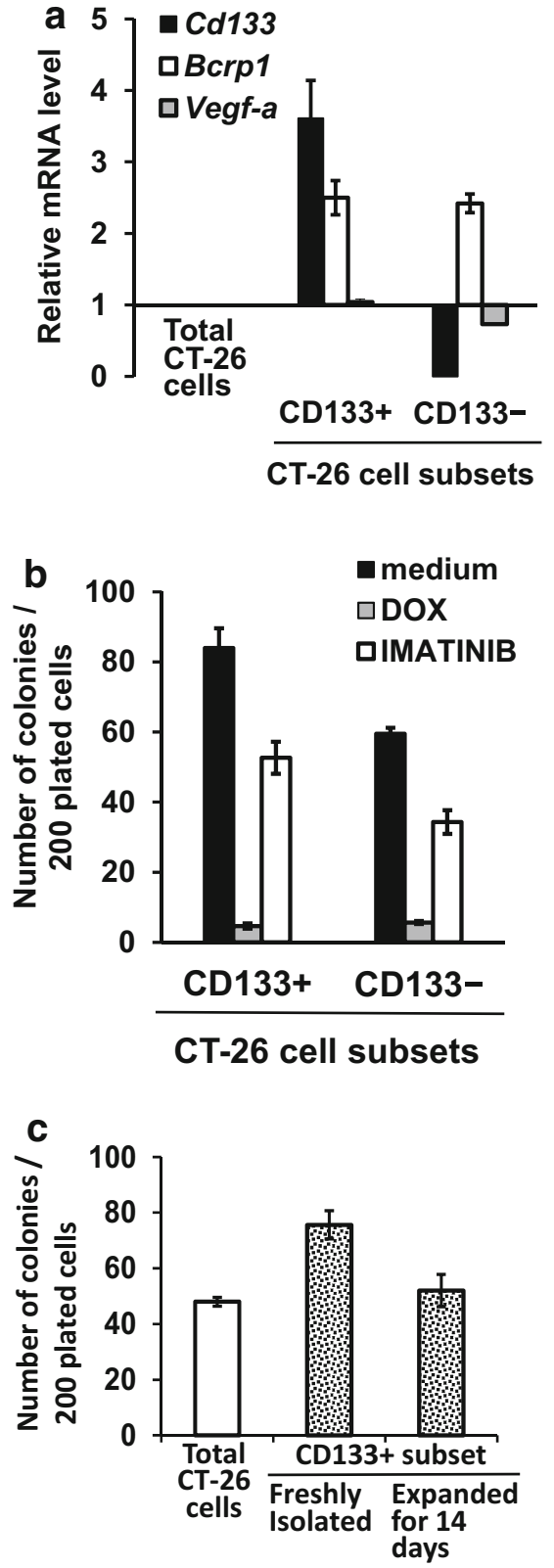

Fig. 9 Comparing of $\mathrm{CD}_{133^{+}}$and $\mathrm{CD} 133^{-}$subsets of chemonaive CT-26 cells obtained by magnetic separation. The relative mRNA expression of Cd133, Bcrp1, and Vegf- $a$ was determined by real-time PCR in the freshly isolated $\mathrm{CD}_{133^{+}}$and $\mathrm{CD} 133^{-}$subsets and compared to control unseparated CT-26 cells. Fold-differences calculated using the $\Delta \Delta C_{\mathrm{T}}$ method are expressed as a range which is the result of incorporating the standard deviation of the $\Delta \Delta C_{\mathrm{T}}$ value into the fold-difference calculation (a). The clonogenic potential of the $\mathrm{CD}_{133^{+}}$subset was higher than the $\mathrm{CD} 133^{-}$subset, but clonogenic cells in both these subsets were similarly sensitive to DOX and to imatinib. The bar graphs indicate mean \pm SD of colony count in each of experimental groups consisting of $n=5$ plates (b). The freshly isolated CD133 ${ }^{+}$subset contained a higher proportion of clonogenic cells compared to unseparated CT-26, but after 2 weeks of culturing the $\mathrm{CD} 133^{+}$subset, the colony formation potential of this subset decreased to the level observed in the unseparated CT-26 cells. The bar graphs indicate mean $\pm \mathrm{SD}$ of colony count in each of experimental groups consisting of $n=3$ plates (c) 


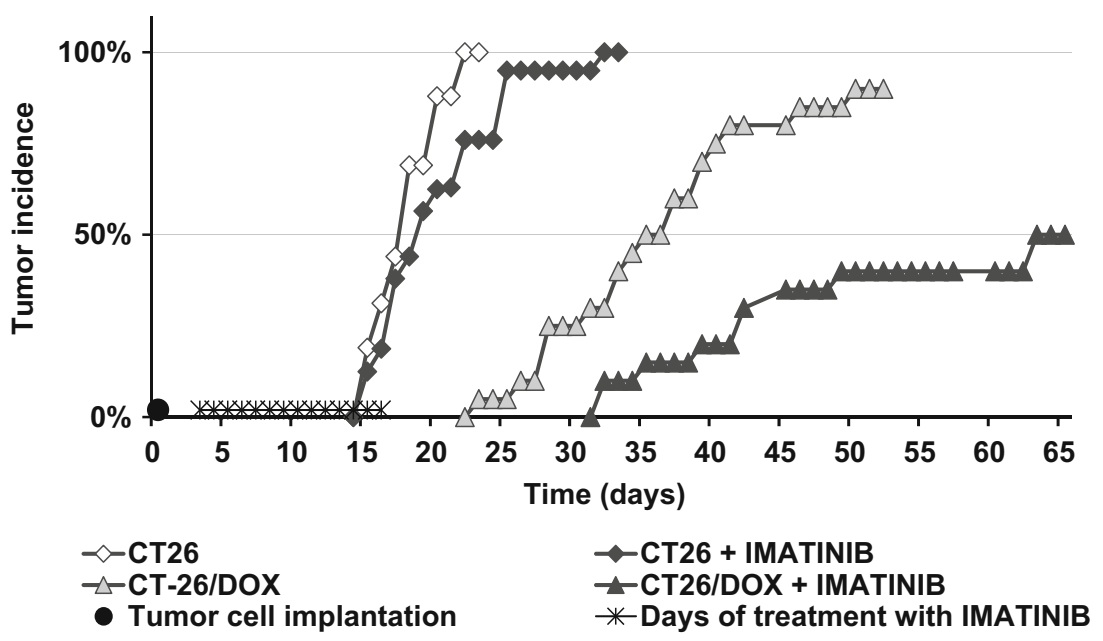

Fig. 10 Comparing the effect of imatinib on tumorigenicity of chemonaive CT-26 and preselected CT-26/DOX cells was evaluated by tumor incidence ( $y$ axis) and time of tumor-free survival ( $x$ axis) of mouse after subcutaneous injection of $5 \times 10^{4}$ cells. Beginning with the third day after cell injection, imatinib was administered daily for

\section{Discussion}

The strategy of combining cytoreductive treatment with the mechanistically distinct treatment targeting the phenotype and metabolic features of CSC/TIC is a matter of dispute. The key issue is whether these treatments should be concomitant or applied sequentially. Several studies have demonstrated synergistic effects of imatinib administration combined with conventional chemotherapeutics. This synergy was explained by various mechanisms, such as an increase in drug uptake by imatinib-induced reduction of interstitial tumor pressure, tumor angiogenesis inhibition, and inhibition of cancer associated fibroblasts (Pietras et al. 2001, 2002; Rezaï et al. 2007). Imatinib reversed acquired and intrinsic resistance to DOX by inducing G2/M arrest and promoted apoptosis by affecting activation of STAT-3dependent NF- $\mathrm{KB}$ and HSP27/p38/AKT survival pathways. Imatinib was also found to prevent acquired chemoresistance by inhibiting ABCB1 function (Sims et al. 2013). Furthermore, drug resistance of cancer cells mediated by $\mathrm{ABCB} 1$ and $\mathrm{ABCB} 2$ was concomitantly inhibited by imatinib (Dohse et al. 2010; Houghton et al. 2004), nevertheless chronic exposure to imatinib at low doses led to reduced intracellular drug accumulation following induction of $\mathrm{ABCB} 1$ and $\mathrm{ABCB} 2$ transporters (Burger et al. 2005).

The increased inhibition of tumor growth observed in preclinical models due to the combination of cytoreductive drugs and imatinib was accompanied by the increased toxicity. A higher toxicity of the concomitant administration of imatinib and cytoreductive drugs as compared to the cytotoxicity of cytoreductive drugs or imatinib the next two weeks, until the first tumor developed in mice injected by control CT-26 cells. Groups of mice injected with CT-26 cells untreated or treated with imatinib each consisted of 10 mice, and groups of mice injected with CT-26/DOX cells and untreated or treated with imatinib each consisted of 20 mice

administered alone was demonstrated in a murine model in vivo (Decaudin et al. 2005). In clinical studies, daily dosing of imatinib with concurrent administration of cytotoxic drugs such as gemcitabine or DOX, at standard doses, was associated with toxicity that was clinically unacceptable (George et al. 2006). To avoid a cumulative toxicity of concomitantly administered cytoreductive drugs and imatinib, a sequential administration of these drugs could thus be applied. What is more, a strong rationale for a sequential administration of cytoreductive drugs and drugs targeting CSC-like cells has been demonstrated by reports on the induction of CSC-like phenotype in tumor cells which survived after treatment with conventional chemotherapeutics. Calcagno et al. (2008) reported that a single step selection with low doses of DOX or etoposide induced multidrug resistance mediated by Bcrp1/ABCG2 being overexpressed in breast, ovarian and colon cancer cells. The overexpression of a wild-type Bcrp1/ABCG2, known as a molecular determinant of a wide variety of stem cells and side-population phenotype (Zhou et al. 2001), was mediated in cancer cells by epigenetic changes following the single-step in vitro selection, whereas a mutation altering the substrate specificity of this transporter had not yet been achieved (Calcagno et al. 2008). Lack of enrichment in cells with putative stem markers, following the single-step in vitro selection, also supported the notion that adaptation prevailed over selection after single-step exposure to an anti-cancer agent. Hu et al. (2012) demonstrated that carboplatin induced self-renewal and pluripotency (Sox 2 and Oct3/4 expression) of hepatocellular carcinoma grown under stem cell conditions. Non$\mathrm{CSC}$, obtained by the exclusion of side population during 


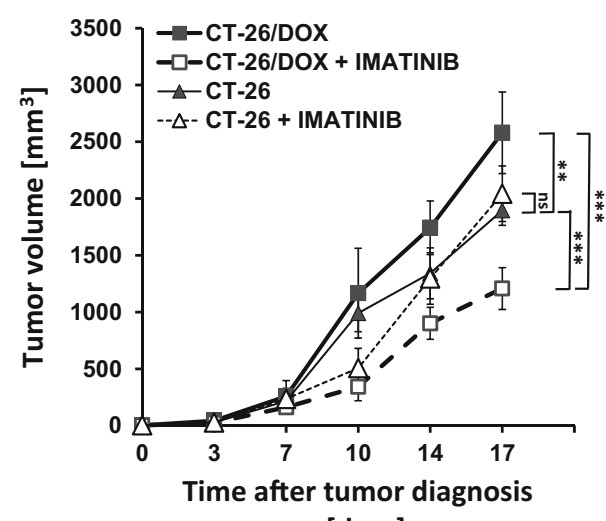

[days]

Fig. 11 Estimating of the effect of imatinib on reducing the growth rate of tumors induced by CT-26 and CT-26/DOX cells. Tumors were measured twice-weekly beginning from palpable tumor diagnosis, following subcutaneous injection of $5 \times 10^{4}$ cells. Tumor growthmeasurement timing was standardized to the day of tumor diagnosis. Points in the plot represent mean \pm SD tumor volume for tumors in each experimental group consisting of six tumors. Statistical differences shown for the measurement performed on day 17 since tumor diagnosis were evaluated by the $t$ test, ${ }^{* *} p<0.01$, ${ }^{* *} p<0.001, n . s$. non-significant

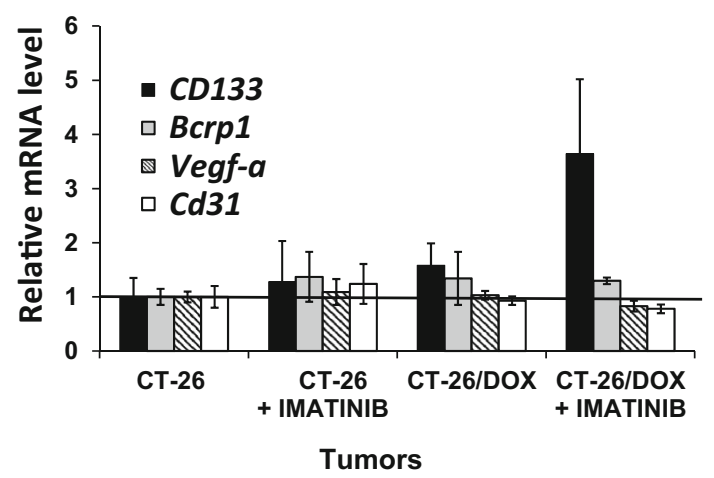

Fig. 12 Estimating the effect of prolonged imatinib treatment on the relative expression of genes associated with stemness (Cd133, Bcrp1) and angiogenesis (Vegf-A, Cd31) in tumors induced by $2 \times 10^{5}$ cells chemonaive CT-26 cells or CT-26/DOX cells. Samples were obtained from tumors that attained ca. 5-8 $\mathrm{mm}$ diameter in mice injected with $2 \times 10^{5}$ cells. The relative mRNA expression was separately determined by real-time PCR in each of the individual tumor samples. The bar graphs indicate mean $\pm \mathrm{SD}$ of fold relative mRNA level in five tumors obtained from mice injected with CT-26 cells and treated with imatinib (CT-26 + imatinib), three tumors from mice injected with CT-26/DOX cells (CT-26/DOX), and in four tumors from mice injected with CT-26/DOX cells and treated with imatinib (CT-26/DOX + imatinib); all were compared to the mean mRNA level in tumors from three control mice (CT-26). Cd133 expression was significantly higher in the "CT-26/DOX + imatinib" group of tumors, compared to the "CT-26 + imatinib" group and to the "CT26/DOX" group as per by the Mann-Whitney test $(p<0.05)$

cell sorting with the use of Hoechst 33342, acquired stem cell-like properties after treatment with carboplatin. The parent tumor can progress from an initially chemosensitive

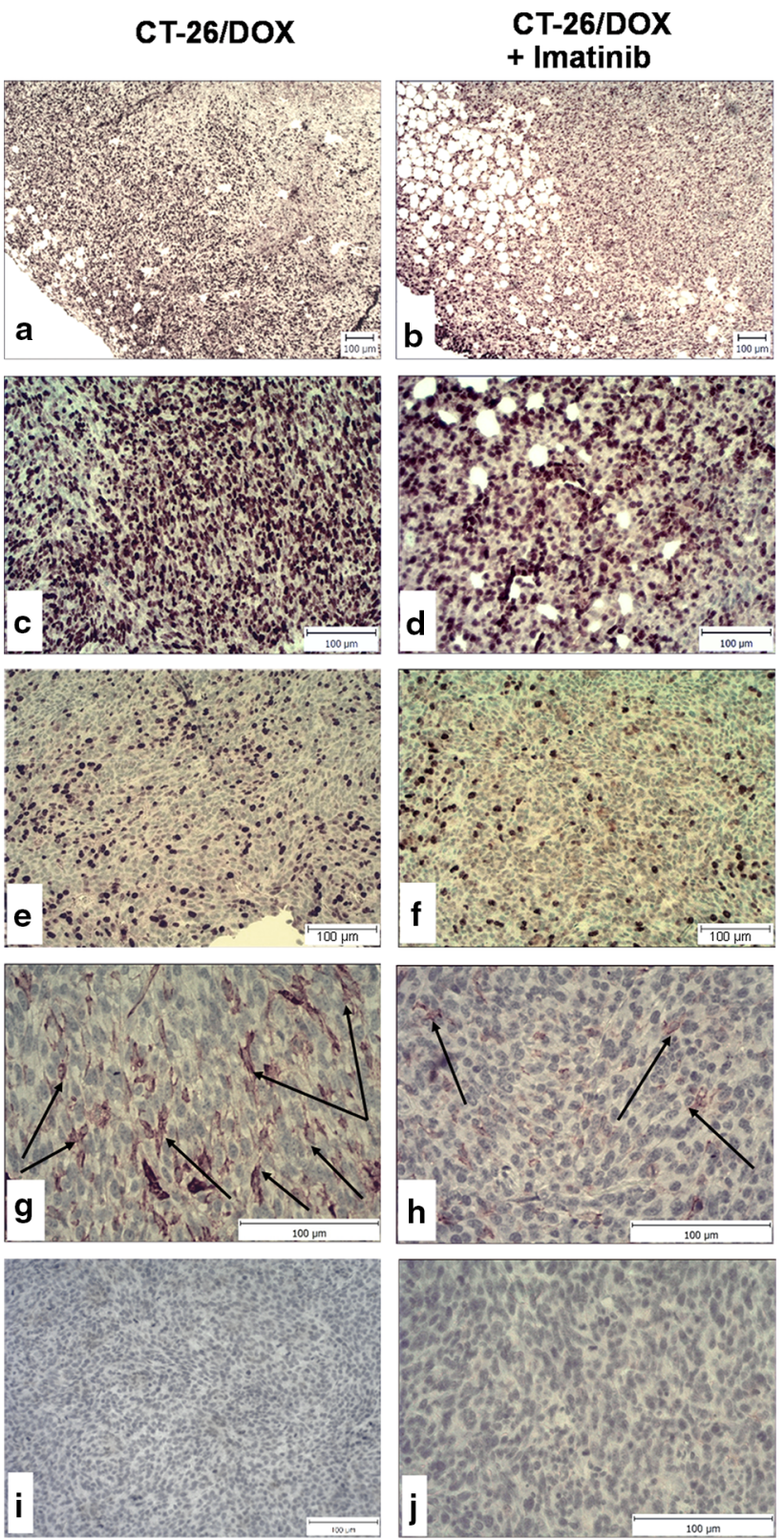

Fig. 13 Imatinib affects the expression of $\mathrm{Ki}-67$ and vimentin inside tumors initiated by preselected CT-26/DOX cells. Representative slices show that the fraction of proliferating cells on the edge of such tumors is larger in mice untreated with imatinib (a, mag. $\times 40$; $\mathbf{c}$, mag. $\times 100$ ) than in mice which underwent prolonged treatment with imatinib $(\mathbf{b}$, mag. $\times 40$, d, mag. $\times 100)$. The proportion of proliferating cells identified by Ki-67 expression was lower in the center of tumors than on the edge of tumors in untreated mice $(\mathbf{e}$, mag. $\times 100)$ or treated with imatinib $(\mathbf{f}$, mag. $\times 100)$. Vimentin expression (indicated by black arrows) was detected only on the edge of tumors, and was lower in mice treated with imatinib $(\mathbf{h}$, mag. $\times 200)$ than in the untreated mice $(\mathbf{g}$, mag. $\times 200)$. The control for pictures $(\mathbf{c}-\mathbf{f})$ is shown in picture $(\mathbf{i}$, mag. $\times 100)$ which presents a section stained with the secondary antibody only. The control for pictures $(\mathbf{g}, \mathbf{h})$ is shown in picture $(\mathbf{j}$, mag. $\times 200)$ 
Fig. 14 Prolonged treatment with imatinib reduced tumor invasive growth and spreading. Representative pictures are shown of the invasive margin of tumors obtained from mice inoculated with CT-26/DOX cells and treated with imatinib (a, mag. $\times 40, \mathrm{H} \& \mathrm{E})$ or receiving vehicle only (b, mag. $\times 40$; c, mag. $\times 100, H \& E$ ).

Tumor buds forming crypt-like structures indicated by black arrows in the invasive front of tumor stained strongly with anti-Ki-67 antibodies (d, mag. $\times 100$ ), but did not stain with antibodies recognizing the $\mathrm{AC} 133$ epitope of the CD133 molecule (e, mag. $\times 100)$, and did not stain with the antivimentin antibody (f, mag. $\times 100$ ) by IHC methods. The controls for pictures $(\mathbf{d}-\mathbf{f})$ are shown in picture $(\mathrm{g}, \mathrm{mag} . \times 100)$ and in picture $(\mathbf{h}$, mag. $\times 40)$. These controls represent sections stained only with the secondary antibody. White arrows show non-specific staining
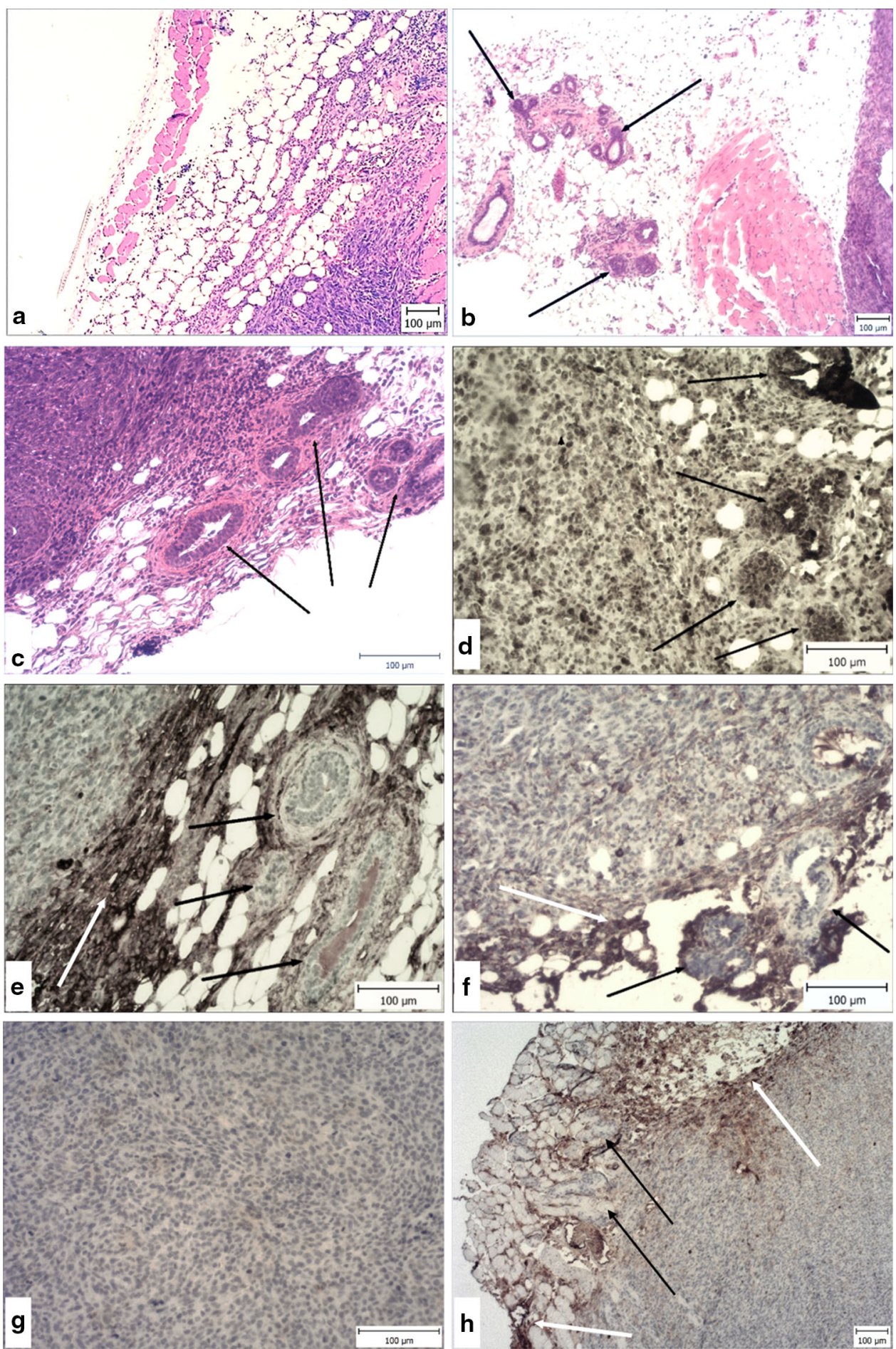

state to one exhibiting increased drug resistance by selecting cells transiently overexpressing genes responsive for drug resistance (Calcagno et al. 2008), but consequently the resistance develops due to selective pressure of multiple cycles promoting the cumulative gain-of-function mutations (Hamilton and Olszewski 2013). These observations suggest that it is reasonable to target CSC phenotype features of cells acquired due to cytoreductive drug exposure.

This study has explored the strategy of sequential treating cancer cells with cytoreductive drug DOX and the receptor tyrosine kinase inhibitor imatinib. DOX and imatinib concentrations used in the in vitro study fall within the range of the concentrations reported in plasma 
after in vivo administration of these drugs (Barpe et al. 2010; Warren et al. 2000; Wolff et al. 2003). In our experiments, the daily dose of imatinib administered to mice was two times lower than the dose used to treat mice by Wolff et al. (2003) that resulted in the $11.8 \mu \mathrm{M}$ imatinib average concentration in plasma. The delayed administration of imatinib was intended to target both pre-existing DOX-refractory CSC/TIC as well as cancer cells which survived after single-step exposure to DOX and acquired stem-like properties due to chemotoxic stress. On the other hand, a suitable time window for imatinib administration was when cancer cells, which acquired stem-like features due to the exposure to DOX, had not yet started to intensely proliferate. We were mindful that while most of the extracellular DOX is removed after replacing the medium containing DOX to one without DOX, the drug remaining within the cells can be trapped or bound to membrane vesicles, and that vesicular sequestration does not seem to stop DOX from reaching the nucleus (Chen et al. 2007). Due to such concerns about subcellular pharmacokinetics of DOX efflux in cancer cells, the medium was exchanged and imatinib added on day 3 after DOX removal from the culture which thereby facilitated a substantial DOX egress from cells. During the 3 days after DOX removal, cells attached to plastic were mostly enlarged, highly granular, and notably bigger compared to actively proliferating chemonaive CT-26 cells. A longer delay before imatinib administration would however let CT-26/DOX cells start renewal manifesting by clone formation and intensive expansion.

We demonstrated complementary inhibitory effects of DOX and imatinib on the clonogenicity of CT-26 cells. Following exposure of chemonaive CT-26 cells to DOX, the majority of clone-initiating cells were eliminated, but DOX preferentially spared clonogenic cells highly sensitive to imatinib or/and sensitized surviving clonogenic cells to imatinib. In contrast to chemonaive clonogenic CT-26 cells, clonogenic CT-26/DOX cells were highly sensitive to imatinib. We found that hypoxic conditions promoted the survival of clone-initiating cells during CT-26 cell exposure to DOX. Hypoxia also stimulated the renewal of CT26/DOX cells, since clonogenicity of CT-26/DOX cells substantially increased under hypoxic conditions. Imatinib effectively inhibited clonogenicity of CT-26/DOX cells under hypoxia and under normoxia. These data imply that imatinib is suitable to target clonogenic CT-26 cells refractory to DOX, especially in the hypoxic environment promoting cells with CSC features. Low oxygen concentration conditions $\left(5 \% \mathrm{O}_{2}\right)$ applied in our study, are more relevant to the physiological stem-cell niche environment than standard culture conditions $\left(20 \% \mathrm{O}_{2}\right)$. It was reported that at $5 \% \mathrm{O}_{2}, \mathrm{HIF} 2 \alpha$ promoted maintenance of those cells with TIC/CSC features, reprogrammed non-CSCs towards a stem-like phenotype, and induced cancer renewal (Heddleston et al. 2009).

CD133 is commonly detected in numerous cancers of epithelial origin, including colorectal cancer. Several reports described CD133 as a potential CSC marker in colorectal cancer because of the association of CD133 membrane overexpression with patient survival (Horst et al. 2008; Kojima et al. 2008; Li et al. 2009; Takahashi et al. 2010; Wang et al. 2009). Cytoplasmic CD133 expression detected by immunohistochemical methods before neoadjuvant concurrent chemoradiotherapy has been inversely correlated with the overall survival (Jao et al. 2012). CD133 is commonly used for isolating CSC, but the relationship of the CD133 molecule to stem or stem-like cells is disputable, since $\mathrm{CD} 133^{-}$cells can also themselves have stem-like properties. Studies of colon cancer cell lines demonstrated that both $\mathrm{CD}_{133^{+}}$and $\mathrm{CD} 133^{-}$cell subpopulations can initialize tumor formation and engage in a bidirectional celltype switching during early colonization in response of being exposed to environmental stressors, including hypoxia (Dittfeld et al. 2009; Hsu et al. 2013; Navarro-Alvarez et al. 2010; Shmelkov et al. 2008).

We investigated whether the CD133-positive CT-26 cell compartment encompasses a reservoir of CSC/TIC. Clonogenic cells were found in $\mathrm{CD}_{133^{+}}$and $\mathrm{CD} 133^{-}$ chemonaive CT-26 cells. A minor subpopulation of chemonaive CT-26 cells expressed Cd133 mRNA and the AC133 epitope of CD133 on the cell surface and displayed a higher clonogenicity then $\mathrm{CD} 133^{-}$chemonaive CT-26 cells. Since both $\mathrm{CD}_{133^{+}}$and $\mathrm{CD} 133^{-}$clonogenic CT-26 cells were sensitive to DOX and to imatinib, CD133 expression neither highly marked chemoresistant cells nor imatinib-resistant cells.

Following exposure to DOX, surface expression of AC133/CD133 was profoundly downregulated while the Cd133 mRNA expression levels highly increased. This suggests that the AC133 epitope of CD133 is not an appropriate as a surface marker of DOX-refractory CT-26 cells capable of starting renewal, and thus suggests that CD133 could not be a sufficiently effective target for therapy aimed to eliminate cells initiating cancer renewal following conventional chemotherapy.

Imatinib downregulated Cd133 mRNA and inhibited reexpression of $\mathrm{AC} 133 / \mathrm{CD} 133$ on the cell surface during renewal of DOX-pretreated CT-26 cells. Our data confirm reports on a loss of CD133 cell surface expression due to hypoxic or chemotoxic stress accompanied with a large increase of Cd133 mRNA (Osmond et al. 2010; Platet et al. 2007). Other studies have reported that $\mathrm{CD} 133^{+}$colorectal cancer cells are not more resistant to 5-fluorouracil than CD133- cells, suggesting that CD133 should therefore not be used as a single CSC/TIC marker in colorectal cancer (Crawford et al. 2003; Hongo et al. 2012). 
We found that the exposure to DOX does not abolish tumorigenicity of CT-26 cells surviving such treatment, but tumorigenic CT-26/DOX cells inoculated heterotopically to mice are strikingly more sensitive to imatinib administered to mice than tumorigenic chemonaive CT-26 cells. This suggests that DOX selectively spares cells highly sensitive to imatinib or sensitizes tumorigenic cells to imatinib. This observation thereby provides a strong rationale for a sequential administration of imatinib following treatment with a conventional chemotherapeutic to impair tumor renewal.

It can be speculated that, in addition to the direct effect of imatinib on colorectal cancer cells in inoculated mice, imatinib could also impair tumor development due to modifying the tumor microenvironment. It has been reported that imatinib inhibits tumor tropism of mesenchymal stem cells and inhibits the phosphorylation of PDGFR- $\beta$ in tumor-associated stromal cells and pericytes by blocking PDGF signaling pathways (Kitadai et al. 2006; Shinagawa et al. 2013). By affecting the interaction between bone marrow-derived mesenchymal stem cells and/or carcinoma-associated fibroblasts and tumor cells, imatinib inhibits the progressive growth of colon cancer. Targeting mechanisms of tumor repopulation initiated by chemoresistant cells thus opens a new perspective for improving clinical outcomes (Kurtova et al. 2015).

Our data suggest that imatinib is suitable for inhibiting tumor growth initiated by colon cancer cells refractory to treatment with conventional chemotherapies. The sequential use of these drugs would be more appropriate than the concomitant use, since cancer cells capable of initiating cancer renewal become sensitized to imatinib due to chemotoxic stress induced by cytoreductive drugs.

Acknowledgments This work was supported by a grant from National Science Centre, Poland (N N402 139738). The authors would like to thank dr Peter Holownia for the language corrections.

\section{Compliance with ethical standards}

Conflict of interest The authors declare that they have no conflict of interest.

Ethical approval The in vivo study has been accepted by the Warsaw Local Ethics Committee for Animal Experimentation.

\section{References}

Abdullah LN, Chow EK (2013) Mechanisms of chemoresistance in cancer stem cells. Clin Transl Med 2:3

Barpe DR, Rosa DD, Froehlich PE (2010) Pharmacokinetic evaluation of doxorubicin plasma levels in normal and overweight patients with breast cancer and simulation of dose adjustment by different indexes of body mass. Eur J Pharm Sci 41:458-463
Betsholtz C, Karlsson L, Lindahl P (2001) Developmental roles of platelet-derived growth factors. BioEssays 23:494-507

Brattain MG, Strobel-Stevens J, Fine D et al (1980) Establishment of mouse colonic carcinoma cell lines with different metastatic properties. Cancer Res 40:2142-2146

Burger H, van Tol H, Brok M et al (2005) Chronic imatinib mesylate exposure leads to reduced intracellular drug accumulation by induction of the ABCG2 (BCRP) and ABCB1 (MDR1) drug transport pumps. Cancer Biol Ther 4:747-752

Calcagno AM, Fostel JM, To KK et al (2008) Single-step doxorubicin-selected cancer cells overexpress the ABCG2 drug transporter through epigenetic changes. $\mathrm{Br} \mathrm{J}$ Cancer 98:1515-1524

Castle JC, Loewer M, Boegel S et al (2014) Immunomic, genomic and transcriptomic characterization of CT26 colorectal carcinoma. BMC Genom 15:190

Chen VY, Posada MM, Zhao L et al (2007) Rapid doxorubicin efflux from the nucleus of drug-resistant cancer cells following extracellular drug clearance. Pharm Res 24:2156-2167

Crawford NP, Colliver DW, Galandiuk S (2003) Tumor markers and colorectal cancer: utility in management. J Surg Oncol 84:239-248

Decaudin D, de Cremoux P, Sastre X et al (2005) In vivo efficacy of STI571 in xenografted human small cell lung cancer alone or combined with chemotherapy. Int J Cancer 113:849-956

Ditkowska J, Wojciechowska U, Zatoński W (2009) Prediction of cancer incidence and mortality in Poland up to year 2025. COI, Warszawa, ISSN 0867-8251. http://onkologia.org.pl/wp-content/ uploads/Prognozy_2025.pdf

Dittfeld C, Dietrich A, Peickert S et al (2009) CD133 expression is not selective for tumor-initiating or radioresistant cell populations in the CRC cell lines HCT-116. Radiother Oncol 92:353-3361

Dohse M, Scharenberg C, Shukla S et al (2010) Comparison of ATPbinding cassette transporter interactions with the tyrosine kinase inhibitors imatinib, nilotinib, and dasatinib. Drug Metab Dispos 38:1371-1380

Dylla SJ, Beviglia L, Park IK, Chartier C et al (2008) Colorectal cancer stem cells are enriched in xenogeneic tumors following chemotherapy. PLoS One 3:e2428

George S, Desai J, Paul Elder J et al (2006) Selective kinase inhibition with daily imatinib intensifies toxicity of chemotherapy in patients with solid tumours. Eur J Cancer 42:864-870

Hamilton G, Olszewski U (2013) Chemotherapy-induced enrichment of cancer stem cells in lung cancer. J Bioanal Biomed S9:003

Heddleston JM, Li Z, McLendon RE et al (2009) The hypoxic microenvironment maintains glioblastoma stem cells and promotes reprogramming towards a cancer stem cell phenotype. Cell Cycle 8:3274-3284

Heldin CH (2012) Autocrine PDGF stimulation in malignancies. Ups J Med Sci 117:83-91

Heldin CH (2013) Targeting the PDGF signaling pathway in tumor treatment. Cell Commun Signal 11:97

Holohan C, Van Schaeybroeck S, Longley DB et al (2013) Cancer drug resistance: an evolving paradigm. Nat Rev Cancer 13:714-726

Hongo K, Tanaka J, Tsuno NH et al (2012) CD133(-) cells, derived from a single human colon cancer cell line, are more resistant to 5-Fluorouracil (FU) than CD133(+) cells dependent on the beta1-integrin signaling. J Surg Res 175:278-288

Horst D, Kriegl L, Engel J et al (2008) CD133 expression is an independent prognostic marker for low survival in colorectal cancer. Br J Cancer 99:1285-1289

Houghton PJ, Germain GS, Harwood FC et al (2004) Imatinib mesylate is a potent inhibitor of the ABCG2 (BCRP) transporter 
and reverses resistance to topotecan and SN-38 in vitro. Cancer Res 64:2333-2337

Hsu CS, Tung CY, Yang CY et al (2013) Response to stress in early tumor colonization modulates switching of CD133-positive and CD133-negative subpopulations in a human metastatic colon cancer cell line, SW620. PLoS One 8:e61133

$\mathrm{Hu}$ X, Ghisolfi L, Keates AC et al (2012) Induction of cancer cell stemness by chemotherapy. Cell Cycle 11:2691-2698

Irollo E, Pirozzi G (2013) CD133: to be or not to be, is this the real question? Am J Transl Res 5:563-568

Jao SW, Chen SF, Lin YS et al (2012) Cytoplasmic CD133 expression is a reliable prognostic indicator of tumor regression after neoadjuvant concurrent chemoradiotherapy in patients with rectal cancer. Ann Surg Oncol 19:3432-3440

Kim Y, Joo KM, Jin J et al (2009) Cancer stem cells and their mechanism of chemo-radiation resistance. Int $\mathrm{J}$ Stem Cells 2:109-114

Kitadai Y, Sasaki T, Kuwai T et al (2006) Targeting the expression of platelet-derived growth factor receptor by reactive stroma inhibits growth and metastasis of human colon carcinoma. Am J Pathol 169:2054-2065

Klonisch T, Wiechec E, Hombach-Klonisch S et al (2008) Cancer stem cell markers in common cancers - therapeutic implications. Trends Mol Med 14:450-460

Kojima M, Ishii G, Atsumi $\mathrm{N}$ et al (2008) Immunohistochemical detection of CD133 expression in colorectal cancer: a clinicopathological study. Cancer Sci 99:1578-1583

Kong D, Li Y, Wang Z et al (2011) Cancer stem cells and epithelialto-mesenchymal transition (EMT)-phenotypic cells: are they cousins or twins? Cancers 3:716-729

Kurtova AV, Xiao J, Mo Q et al (2015) Blocking PGE2-induced tumour repopulation abrogates bladder cancer chemoresistance. Nature 517:209-213

Li CY, Li BX, Liang Y et al (2009) Higher percentage of CD133 ${ }^{+}$ cells is associated with poor prognosis in colon carcinoma patients with stage IIIB. J Transl Med 7:56

Lipiec A, Miłoszewska J, Przybyszewska M et al (2008) CT26 colon cancer cell line as a model for antitumor combined therapy. Acta Biochem Pol 55(suppl 3):290. http://www.actabp.pl/\#Archiwum?./ supl/3_2008.html

Navarro-Alvarez N, Kondo E, Kawamoto H et al (2010) Isolation and propagation of a human CD133(-) colon tumor-derived cell line with tumorigenic and angiogenic properties. Cell Transplant 19:865-877

Osmond TL, Broadley KW, McConnell MJ (2010) Glioblastoma cells negative for the anti-CD133 antibody AC133 express a truncated variant of the CD133 protein. Int J Mol Med 25:883-888

Pietras K, Ostman A, Sjöquist M et al (2001) Inhibition of plateletderived growth factor receptors reduces interstitial hypertension and increases transcapillary transport in tumors. Cancer Res 61:2929-2934
Pietras K, Rubin K, Sjöblom T et al (2002) Inhibition of PDGF receptor signaling in tumor stroma enhances antitumor effect of chemotherapy. Cancer Res 62:5476-5484

Platet N, Liu SY, Atifi ME et al (2007) Influence of oxygen tension on CD133 phenotype in human glioma cell cultures. Cancer Lett 258:286-290

Rezaï K, Lokiec F, Grandjean I et al (2007) Impact of imatinib on the pharmacokinetics and in vivo efficacy of etoposide and/or ifosfamide. BMC Pharmacol 7:13

Shinagawa K, Kitadai Y, Tanaka M et al (2013) Stroma-directed imatinib therapy impairs the tumor-promoting effect of bone marrow-derived mesenchymal stem cells in an orthotopic transplantation model of colon cancer. Int J Cancer 132:813-823

Shmelkov SV, Butler JM, Hooper AT et al (2008) CD133 expression is not restricted to stem cells, and both $\mathrm{CD} 133^{+}$and $\mathrm{CD} 133^{-}$ metastatic colon cancer cells initiate tumors. J Clin Invest 118:2111-2120

Siegel R, Ma J, Zou Z et al (2014) Cancer statistics, 2014. CA Cancer J Clin 64:9-29

Sims JT, Ganguly SS, Bennett $H$ et al (2013) Imatinib reverses doxorubicin resistance by affecting activation of STAT3-dependent NF- $\kappa$ B and HSP27/p38/AKT pathways and by inhibiting ABCB1. PLoS One 8:e55509

Szczepek W, Samson-Lazinska D, Zagrodzki B et al (2005) Preparation of crystalline methanesulfonic acid addition salts of imatinib. PTC Int Appl WO2005095379 A2 20051013

Szczepek W, Luniewski W, Kaczmarek L et al (2006) A process for preparation of imatinib base. PTC Int Appl WO 2006071130(A2):20060706

Takahashi S, Kamiyama T, Tomaru U et al (2010) Frequency and pattern of expression of the stem cell marker CD133 have strong prognostic effect on the surgical outcome of colorectal cancer patients. Oncol Rep 24:1201-1212

van der Horst G, Bos L, van der Pluijm G (2012) Epithelial plasticity, cancer stem cells, and the tumor-supportive stroma in bladder carcinoma. Mol Cancer Res 10:995-1009

Wang Q, Chen ZG, Du CZ et al (2009) Cancer stem cell marker $\mathrm{CD}_{133^{+}}$tumour cells and clinical outcome in rectal cancer. Histopathology 55:284-293

Warren KE, McCully CM, Walsh TJ et al (2000) Effect of fluconazole on the pharmacokinetics of doxorubicin in nonhuman primates. Antimicrob Agents Chemother 44:1100-1101

Wolff NC, Richardson JA, Egorin M et al (2003) The CNS is a sanctuary for leukemic cells in mice receiving imatinib mesylate for Bcr/Abl-induced leukemia. Blood 101:5010-5013

Zhou S, Schuetz JD, Bunting KD et al (2001) The ABC transporter $\mathrm{Bcrp} 1 / \mathrm{ABCG} 2$ is expressed in a wide variety of stem cells and is a molecular determinant of the side-population phenotype. Nat Med 7:1028-1034 